\title{
DISPONIBILIDAD DE MATERIAS PRIMAS LÍTICAS EN LA COSTA NORORIENTAL DEL ESTRECHO DE MAGALLANES (CHILE). UNA APROXIMACIÓN EXPLORATORIA
}

\author{
JUDITH CHARLINª \& MASSIMO D’ORAZIOb
}

\begin{abstract}
RESUMEN
Se caracteriza la disponibilidad de materias primas líticas en la costa nororiental del estrecho de Magallanes (Magallanes, Chile) a partir de la información obtenida en nueve muestreos de roca realizados entre bahía Posesión y bahía Laredo siguiendo la metodología propuesta por Franco y Borrero (1999) para el muestreo de fuentes secundarias de aprovisionamiento lítico. Se describe la abundancia, riqueza, calidad para la talla y tamaño de las rocas disponibles en los depósitos costeros. La determinación microscópica de cortes delgados de roca permitió la identificación petrográfica de distintos tipos, especialmente entre las rocas de grano fino oscuras, los cuales corresponden a variedades diferentes a aquellas más frecuentes en el campo volcánico Pali Aike. Los nuevos datos se discuten en el marco de la información glaciológica y arqueológica disponible para el área y en una escala mayor, en comparación con los resultados previos obtenidos en el campo volcánico Pali Aike.
\end{abstract}

PALABRAS CLAVE: materias primas líticas, disponibilidad, estrecho de Magallanes, campo volcánico Pali Aike.

\section{LITHIC RAW MATERIALS AVAILABILITY IN THE NORTHEASTERN COAST OF MAGELLAN STRAIT (CHILE). AN EXPLORATORY APPROACH}

\begin{abstract}
Lithic raw materials availability in the northeastern coast of the strait of Magellan (Magellan, Chile) is characterized by means of nine rock samples collected between Posesión and Laredo bays following Franco and Borrero's (1999) sampling methodology. Abundance, richness, flintknapping quality and size of rocks in coastal deposits are described. Thin section microscopic determinations allowed us to identify several types of lithic raw materials, especially of fine-grained dark rocks, which are different to those usually present in the Pali Aike volcanic field.

These new data are discussed in relationship with the glaciological and archaeological information

CONICET-IMHICIHU, UBA. Saavedra $155^{\circ}$ piso Ciudad Autònoma de Buenos Aires, Argentina. judith.charlin@gmail.com

b_Dipartimento di Scienze della Terra, Universidad de Pisa, Pisa, Italia. dorazio@dst.unipi.it
\end{abstract}


available for the area, and in a greater scale in comparison to previous results obtained from the Pali Aike volcanic field.

KEY WORDS: lithic raw materials, availability, strait of Magellan, Pali Aike volcanic field.

\section{INTRODUCCIÓN}

Las investigaciones llevadas a cabo en el campo volcánico Pali Aike (CVPA, Barberena, 2002, 2008; Barberena et al. 2007; Bird, 1988; Borrero \& Barberena, 2006; Borrero \& Charlin, 2010; Charlin, 2007, 2009; L'Heureux, 2008, entre otros) y a lo largo de la costa nororiental del estrecho de Magallanes (Constantinescu et al. 1999; Laming-Emperaire, 1968; Martinic, 1984a, 1984b; Massone, 1979, 1983, 1984; Prieto, 1988) han señalado la interacción entre ambos espacios durante el Holoceno tardío. Esta afirmación se basa principalmente en el estudio de la distribución de restos marinos hacia el interior del CVPA (Barberena, 2008; Barberena et al. 2004, 2008; Borrero \& Barberena, 2006; L'Heureux, 2008), en los análisis de isótopos estables sobre restos óseos humanos (Barberena, 2002, 2008; Borrero \& Barberena, 2006; Borrero et al. 2001) y en el grado de reducción de las materias primas líticas en sitios del CVPA localizados a distintas distancias de la costa (Charlin 2007, 2009).

En base a estos antecedentes, en particular el último, surgió la necesidad de evaluar la disponibilidad de materias primas líticas a lo largo del estrecho de Magallanes, especialmente de las rocas de grano fino oscuras (RGFO, Charlin, 2005), y así contar con muestras de rocas para comparar con aquellas disponibles en las fuentes potenciales de aprovisionamiento del CVPA (Charlin, 2009). En este trabajo se presenta la información obtenida a partir de nueve muestreos de roca realizados en la costa del estrecho de Magallanes (Magallanes, Chile) entre bahía Posesión y bahía Laredo, siguiendo la metodología propuesta por Franco y Borrero (1999) para el muestreo de fuentes secundarias de aprovisionamiento lítico. Los datos que aquí se presentan son exploratorios, debido al pequeño tamaño de la muestra, e incluyen información sobre la abundancia, riqueza, tamaño y calidad para la talla (Aragón \& Franco, 1997) de las rocas disponibles en diferentes loci de la costa nororiental del estrecho de Magallanes. Asimismo, se sintetiza la información glaciológica y arqueológica del área y se evalúan las similitudes y diferencias en la oferta de rocas en relación con el CVPA.

\section{MARCO GEOLÓGICO: \\ LAS GLACIACIONES Y LOS DEPÓSITOS DE GRAVA EN PATAGONIA MERIDIONAL}

El número y extensión de las glaciaciones y el origen y características de los depósitos de grava han constituido un tema de debate en las investigaciones geológicas de la región patagónica desde las primeras observaciones realizadas por Darwin (Benn \& Clapperton, 2000; Clapperton, 1993; Clapperton et al. 1995; Feruglio, 1950; Fidalgo \& Riggi, 1965, 1970; Meglioli 1992; Rabassa \& Clapperton, 1990; Sudgen et al. 2005). La información glaciológica disponible para el área de estudio señala la importancia en extensión y exposición de los depósitos de drift en ambas costas del estrecho de Magallanes (Benn \& Clapperton, 2000; Clapperton et al. 1995; Marangunic, 1974; Meglioli, 1992, entre otros). En particular, para Patagonia meridional y Tierra del Fuego, Meglioli (1992) ha propuesto un modelo regional de geología glacial. Según sus estudios, en la faja costera del estrecho de Magallanes, de este a oeste, es posible diferenciar depósitos de drift de las glaciaciones Cabo Vírgenes -especialmente en la zona entre punta Dungeness y San Gregorio-, Punta Delgada -que rodea enteramente bahía Posesión-, y Primera y Segunda Angostura, a partir de los accidentes topográficos respectivos (Meglioli, 1992). Esta información señala las potencialidades de esta zona como fuente secundaria de aprovisionamiento lítico (Nami, 1985).

Si nos remontamos a los antecedentes de los estudios geológicos en el área, la primera cartografía de los depósitos glacigénicos en Patagonia meridional y Tierra del Fuego fue realizada por 
Caldenius (1932), quien diferenció cuatro sistemas morénicos (Inicioglacial, Daniglacial, Gotiglacial y Finiglacial, de más antiguo a más moderno) que correlacionó con los depósitos de drift escandinavos. La cronología de las glaciaciones se determinó a través de los varves acumulados en lagos asociados con morenas. De este modo, todos los cinturones morénicos, excepto el más externo -Inicioglaciar-, fueron asignados a la última glaciación. Con respecto al Inicioglaciar, Caldenius sostuvo que representaba una glaciación más antigua.

Las primeras dataciones radiométricas de los eventos glaciarios en el sur de Sudamérica fueron obtenidas por Mercer (1976), quien demostró que había glaciaciones más antiguas. Mercer encontró morenas interestratificadas con flujos de basalto en la cuenca del río Santa Cruz y en el estrecho de Magallanes. A través de la datación de los mismos fue posible asignar edades límite a los depósitos glaciarios (entre ca. 1.0-1.2 millones de años, Ma en adelante). Mercer (1976) denominó a ésta glaciación "la gran glaciación patagónica", dado que los glaciares avanzaron $200 \mathrm{~km}$ hacia el este del frente montañoso, alcanzando la plataforma continental atlántica. De esta forma, los hielos formaron un campo continuo a lo largo de los Andes, al sur de la región de los lagos chilenos (Rabassa \& Clapperton, 1990).

Posteriormente, se recuperaron registros de glaciaciones más antiguas cerca del lago Viedma. Se trata de depósitos de till entre lavas datadas en 7.0-4.6 Ma (Mercer \& Sutter, 1981, citado en Rabassa \& Clapperton, 1990). Éstos son los depósitos glaciares conocidos más antiguos de Patagonia.

En nuestra área de estudio, la distribución de los depósitos glaciarios y sus edades fueron estudiados por Meglioli (Meglioli, 1992, 1994; Meglioli et al. 1990). El objetivo de sus investigaciones fue precisar las cronologías de los eventos glaciarios y su extensión en el espacio para el lapso comprendido entre 3.5 Ma-25.000 años AP. Asimismo, las fluctuaciones de los glaciares durante la última glaciación y la transición del último glacial al integlacial, fueron estudiadas en profundidad por McCulloch et al. (2000, 2005a y b) y Sudgen et al. (2005), entre otros, quienes contemplaron diferentes proxies. A continuación sintetizamos los resultados alcanzados por Meglioli, para complementar luego con información obtenida por otras investigaciones.

Meglioli (1992) empleó múltiples técnicas de datación relativa (tales como el desarrollo de anillos de meteorización en las gravas, la geometría y morfología de las morenas, el desarrollo del perfil del suelo, etc.) para asignarle una edad a los depósitos glaciarios, las cuales fueron confirmadas a través de fechados absolutos de K/Ar y ${ }^{40} \mathrm{Ar} /{ }^{39} \mathrm{Ar}$ realizados sobre flujos de basalto que se encontraban por arriba, por debajo o interestratificados con los depósitos glaciarios.

En base a estos estudios, y para el lapso considerado, Meglioli (1992) propuso un modelo de seis glaciaciones para el extremo sur de Patagonia y Tierra del Fuego. Así, las glaciaciones diferenciadas, de más antiguas a más modernas, son: 1. Río Grande (> 1.86 Ma $<2.05 \mathrm{Ma}$ ), 2. Sierra de los Frailes (> 1.07 Ma < $1.04 \mathrm{Ma}$ ), 3. Cabo Vírgenes ( $\geq 0.45 \mathrm{Ma}<1.07$ Ma), 4. Punta Delgada, 5. Primera Angostura y 6. Segunda Angostura (> 16.000 años AP).

Las glaciaciones de Punta Delgada y Primera Angostura no presentan edades radiométricas, ya que no se encontraron depósitos de drift en contacto con basaltos. Una edad de aproximadamente 140.000 años fue asignada a la glaciación Primera Angostura en correlación con depósitos datados del norte de Patagonia (Meglioli, 1992).

Los glaciares que se extendieron sobre el sur de Patagonia y Tierra del Fuego siguieron seis ejes principales: el valle del río Gallegos, el estrecho de Magallanes, el seno Skyringlaguna Blanca, el seno Otway-Oazy Harbour, la bahía Inútil-bahía San Sebastián y el lago Cami (Fagnano) (Meglioli, 1992). Por este motivo, Meglioli (1992) diferenció los depósitos de drift de cada glaciación según los lóbulos glaciarios y correlacionó unos con otros en un modelo regional (Tabla 1). Las glaciaciones han sido denominadas según la nomenclatura de los drifts del lóbulo del estrecho de Magallanes debido a la posición central del mismo y a la extensión, integridad y buen desarrollo morfológico de sus 
Tabla 1. Modelo glacial regional para Patagonia meridional y Tierra del Fuego (tomado de Meglioli, 1992).

\begin{tabular}{|c|c|c|c|c|c|c|}
\hline \multicolumn{7}{|c|}{ CORRELATION OF GLACIAL DEPOSITS OF TIERRA DEL FUEGO AND SOUTHERNMOST PATAGONIA } \\
\hline \multirow{2}{*}{$\begin{array}{l}\text { REGIONAL } \\
\text { MODEL }\end{array}$} & \multicolumn{3}{|c|}{ SOUTHERN PATAGONIA } & \multirow{2}{*}{$\begin{array}{c}\text { ESTRECHO } \\
\text { DE } \\
\text { MAG ALL AFES }\end{array}$} & \multicolumn{2}{|c|}{ TIERRA DEL FUEGO } \\
\hline & $\begin{array}{c}\text { RIO G ALLEGOS } \\
\text { Y ALLEY }\end{array}$ & SENO OTYAY & SENO SKYRING & & ВАHIA INUTIL & LAGO CAMI \\
\hline $\begin{array}{l}\text { SEGUNDA } \\
\text { ANGOSTURA } \\
\text { GLACIATION }\end{array}$ & $\begin{array}{l}\text { SENO ALMIRANTE } \\
\text { MONTT DRIFT }\end{array}$ & $\begin{array}{l}\text { SENO OTWAY } \\
\text { DRIFT }\end{array}$ & $\begin{array}{c}\text { SENO SKYRING } \\
\text { DRIFT }\end{array}$ & $\begin{array}{l}\text { SEGUNDA } \\
\text { ANGOSTURA } \\
\text { DRIFT }\end{array}$ & $\begin{array}{c}\text { BAHIA INUTIL } \\
\text { DRIFT }\end{array}$ & $\begin{array}{l}\text { LAGO CAMI } \\
\text { DRIFT }\end{array}$ \\
\hline $\begin{array}{l}\text { PRIMERA } \\
\text { ANGOSTURA } \\
\text { GLACIATION }\end{array}$ & $\begin{array}{l}\text { RIO TURBIO } \\
\text { DRIFT }\end{array}$ & $\begin{array}{c}\text { OAZY HARBOUR } \\
\text { DRIFT }\end{array}$ & $\begin{array}{l}\text { RIO VERDE } \\
\text { DRIFT }\end{array}$ & $\begin{array}{l}\text { PRIMERA } \\
\text { ANGOSTURA } \\
\text { DRIFT }\end{array}$ & $\begin{array}{l}\text { LAGUNAS } \\
\text { SECAS } \\
\text { DRIFT }\end{array}$ & $\begin{array}{l}\text { LAGO } \\
\text { CHEPELMUT } \\
\text { DRIFT }\end{array}$ \\
\hline $\begin{array}{l}\text { PUNTA } \\
\text { DELGADA } \\
\text { GLACIATION }\end{array}$ & $\begin{array}{c}\text { NOT } \\
\text { RECOGNIZED }\end{array}$ & $\begin{array}{c}\text { DINAMARQUERO } \\
\text { DRIFT }\end{array}$ & $\begin{array}{c}\text { LAGUNA BLANCA } \\
\text { DRIFT }\end{array}$ & $\begin{array}{l}\text { PUNTA } \\
\text { DELGADA } \\
\text { DRIFT }\end{array}$ & $\begin{array}{l}\text { SIERRAS DE } \\
\text { SAN SEBASTIAN } \\
\text { DRIFT }\end{array}$ & $\begin{array}{c}\text { RIO VALDEZ } \\
\text { DRIFT ? }\end{array}$ \\
\hline $\begin{array}{l}\text { CABO } \\
\text { YIRGENES } \\
\text { GLACIATION }\end{array}$ & $\begin{array}{l}\text { GLENCROSS } \\
\text { DRIFT }\end{array}$ & $\begin{array}{l}\text { RIO CIAIKE } \\
\text { DRIFT }\end{array}$ & $\begin{array}{l}\text { RIO ZURDO } \\
\text { DRIFT }\end{array}$ & $\begin{array}{l}\text { CABO } \\
\text { YIRGENES } \\
\text { DRIFT }\end{array}$ & $\begin{array}{l}\text { RIO CULLEN } \\
\text { DRIFT }\end{array}$ & \\
\hline $\begin{array}{l}\text { SIERRA DE } \\
\text { LOS FRAILES } \\
\text { GLACIATION }\end{array}$ & $\begin{array}{l}\text { BELLA VISTA } \\
\text { DRIFT }\end{array}$ & $\begin{array}{l}\text { PALI AIKE } \\
\text { DRIFT }\end{array}$ & $\begin{array}{l}\text { PALI AIKE } \\
\text { DRIFT }\end{array}$ & $\begin{array}{l}\text { SIERRA DE } \\
\text { LOS FRAILES } \\
\text { DRIFT }\end{array}$ & $\begin{array}{l}\text { PAMPA DE } \\
\text { BETA DRIFT }\end{array}$ & \\
\hline $\begin{array}{l}\text { RIO GRANDE } \\
\text { GLACIATION }\end{array}$ & $\begin{array}{c}\text { NOT } \\
\text { RECOGNIZED }\end{array}$ & $\begin{array}{c}\text { NOT } \\
\text { RECOGNIZEC }\end{array}$ & $\begin{array}{c}\text { NOT } \\
\text { RECOGNIZED }\end{array}$ & $\begin{array}{l}\text { RIO GRANDE } \\
\text { DRIFT }\end{array}$ & $\begin{array}{l}\text { RIO GRANDE } \\
\text { DRIFT }\end{array}$ & \\
\hline
\end{tabular}

unidades.

La primera glaciación que afecta nuestra área de estudio es Sierra de los Frailes (1.07 \pm 0.03/1.4 $\pm 0.1 \mathrm{Ma})$. Si bien la glaciación más antigua en el modelo de Meglioli es Río Grande, la misma fue registrada solamente en Tierra del Fuego, a la cual cubrió por completo. En este sentido, los estudios de Meglioli apoyan lo sostenido por Caldenius en cuanto a la extensión de las dos glaciaciones más antiguas identificadas por este investigador. Meglioli confirmó esta observación, pero les adjudicó una edad más antigua (Meglioli, 1994; Meglioli et al. 1990).

Sierra de los Frailes es la glaciación que alcanza la mayor extensión hacia el norte, sobre el continente, y hacia el este, alcanzando la actual plataforma submarina del océano Atlántico (Fig. 1). La misma fue la glaciación más grande que tuvo lugar en Sudamérica durante el Pleistoceno temprano y se corresponde con el "Inicioglaciar" de Caldenius (1932) y la "Greatest Patagonian Glaciation" de Mercer (1976). Los depósitos de esta glaciación se encuentran cubriendo las superficies más altas y las pampas no disectadas; no se registran al interior de los valles lo cual sugiere que su depositación es previa a la formación de las redes fluviales. Posiblemente esta glaciación sea la responsable del cavado del estrecho de Magallanes (Meglioli, 1992).

La glaciación Cabo Vírgenes (de edad Daniglacial, sensu Caldenius, 1932) estuvo presente en la región a través de dos lóbulos glaciarios, que cubrieron el área de los senos de Otway y Skyring y el estrecho de Magallanes hacia el norte y la depresión de bahía Inútil-bahía San Sebastián hacia el sur (Coronato et al. 2004; Meglioli, 1992).

La glaciación Punta Delgada (también Daniglacial en el marco de Caldenius), al igual que la anterior estuvo formada por dos lóbulos, pero de menor extensión, alcanzando bahía Posesión y punta Catalina en el e strecho de Magallanes y la costa sur de bahía San Sebastián en Tierra del Fuego (Coronato et al. 2004; Meglioli, 1992).

$$
\text { La glaciación Primera Angostura }
$$
(Gotiglacial sensu Caldenius, 1932) se extendió a través de lóbulos de menor tamaño, que se desarrollaron separados uno del otro. Así, los glaciares de Skyring, Otway y Magallanes fueron 
independientes. Finalmente, la última glaciación, denominada Segunda Angostura (Finiglacial sensu Caldenius, 1932) cubrió la zona de islas que hoy se encuentran emergidas. Como en el caso anterior, los lóbulos se mantuvieron independientes, tanto en Patagonia continental como en Tierra del Fuego (Meglioli, 1992).

Luego de la última glaciación, en los momentos de transición al interglacial (Tardiglacial/ Holoceno), McCulloch et al. (2000) señalan la ocurrencia de un avance glaciar significativo (de 80 $\mathrm{km}$ ) en el estrecho de Magallanes entre 12.700 y 10.000 años AP que coincide con los intervalos de enfriamiento denominados Antarctic Cold reversal y Younger Dryas, en los hemisferios sur y norte respectivamente. Dicho avance se encontraría relacionado con el incremento de las precipitaciones resultado de la localización de los vientos del oeste (westerlies) en su posición actual y señala una sincronicidad en la estructura de los cambios climáticos entre el hemisferio norte y sur (McCulloch et al. 2000).

La sincronía o asincronía de los cambios climáticos entre ambos hemisferios es un tema de debate entre los especialistas (ver referencias en Sudgen et al. 2005) y principalmente depende de la escala y los mecanismos considerados. Así, se ha sugerido, por un lado, una sincronía entre norte y sur en el último máximo glacial y posterior deglaciación en una escala orbital (McCulloch et al. 2000, 2005a y b; Sudgen et al. 2005) y por el otro, se detectaron cambios desfasados entre ambos hemisferios en la última transición glacialinterglacial en una escala de milenios, debido a la mayor influencia en el sur de Patagonia de la temperatura oceánica superficial, el hielo marino y los vientos del oeste (McCulloch et al. 2005b; Sudgen et al. 2005).

Lo particular del último avance glaciar en el estrecho de Magallanes, en comparación con los glaciares de latitudes más septentrionales (40$43^{\circ} \mathrm{S}$ y $\left.45-50^{\circ} \mathrm{S}\right)$, es que el hielo perduró en cotas bajas durante 4.000 años más (McCulloch et al. 2000, p. 413). La información paleoecológica obtenida a ambos lados del estrecho de Magallanes es consistente con este panorama (McCulloch et al. 2000). Posteriores análisis de isótopos cosmogénicos en bloques de roca, nuevas dataciones radiocarbónicas y revisión de las viejas contaminadas por carbón pobre en $\mathrm{C}^{14}$, estudios de racemización de aminoácidos y tefrocronología, permitieron afinar la cronología de las fluctuaciones glaciales durante el último máximo glacial y la transición al Holoceno (McCulloch et al. 2005a). Así, se identificaron cinco avances (A-E): el primero es previo al último máximo glacial (> 90.000 AP) y éste se encuentra representado por el avance $\mathrm{B}$ (con dataciones posteriores al 31.250 hasta 25.200-23.100 años AP calibrados, AAP cal. en adelante). Los avances subsiguientes son menos extensivos y se ubican entre 22.400-20.300 AAP cal. (avance C), 17.700-17.600 AAP cal. (el avance D habría comenzado antes de esta fecha, que es la de su finalización) y 15.500-11.770 AAP cal. (avance E). Este último avance coincide, por un lado, con el Antarctic Cold reversal en el hemisferio sur, y su retracción con el máximo del Younger Dryas en el hemisferio norte, lo cual apoya lo señalado anteriormente sobre la no coincidencia de los cambios climáticos entre ambos hemisferios en la escala de milenios (McCulloch et al. 2005a). En dicha escala, el balance oceánico, vinculado con la circulación termohalina, es el mecanismo que rige los cambios climáticos, como así también los factores regionales (McCulloch et al. 2005a). Los avances A-E se enmarcarían en la glaciación Segunda Angostura en el esquema de Meglioli (1992), aunque solamente el avance A alcanza dicho accidente topográfico en Patagonia continental (ver Fig. 1 en McCulloch et al. 2005a, p. 290 o Fig. 2 en McCulloch \& Morello, 2009, p. 121). A partir del avance $B$ (último máximo glacial), el lóbulo glacial se restringe al límite sur de bahía Laredo en Patagonia continental, extendiéndose principalmente sobre el área NW de la actual Tierra del Fuego (península Juan Mazia, bahía Gente Grande, Porvenir y bahía Inútil).

En este punto cabe señalar que los depósitos glaciales acumulados en lo que hoy son ambas márgenes del estrecho de Magallanes fueron removidos y re-depositados por los lagos proglaciales y los ríos de desagüe que se formaron durante la deglaciación en cuencas erosionadas previamente por el hielo, como así también por la transgresión marina que dio lugar a la formación definitiva del estrecho de Magallanes hacia el Holoceno medio (McCulloch et al. 2005b; McCulloch \& Morello, 2009). Esto ocurrió ca. 


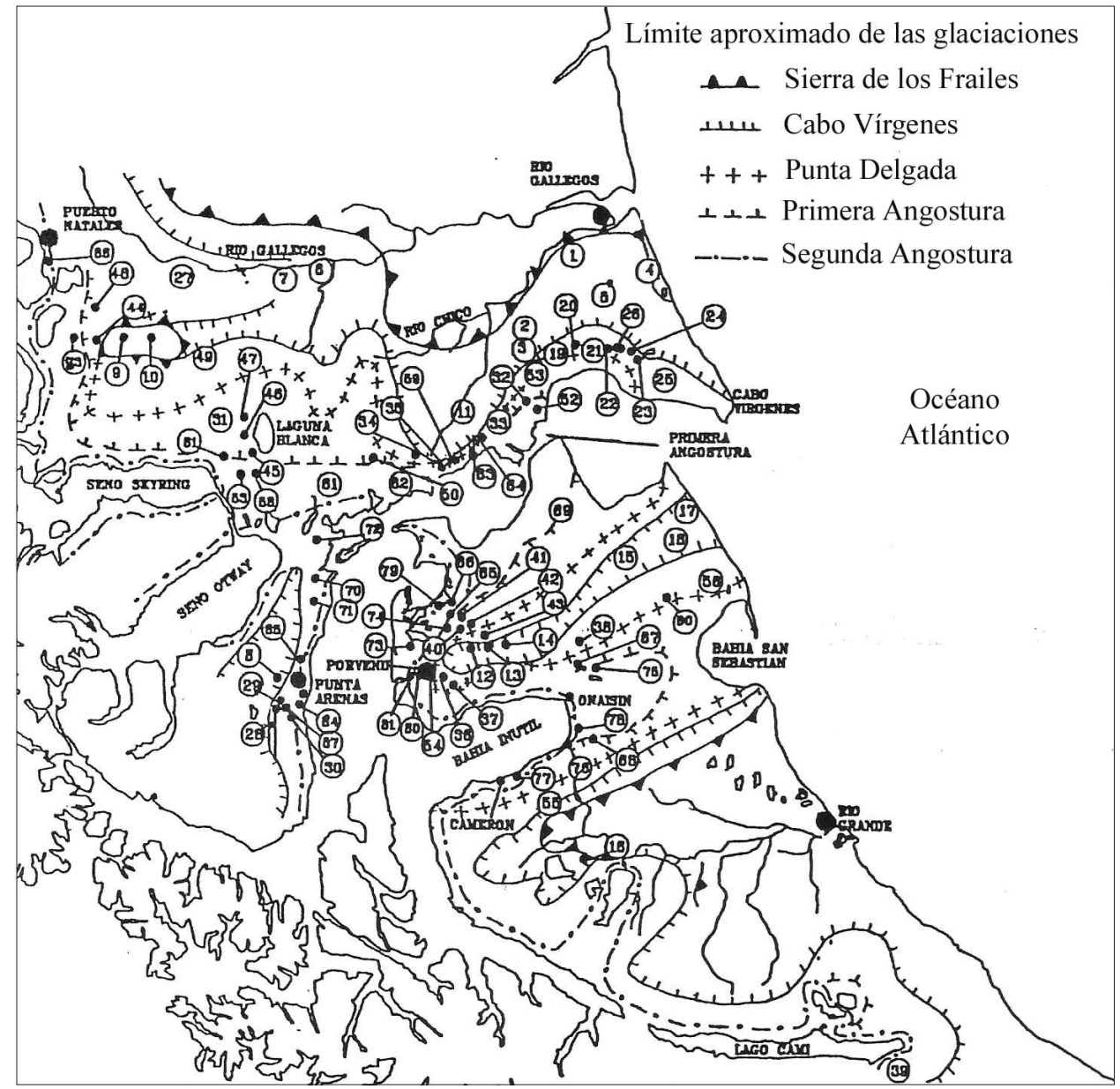

Fig. 1. Límites aproximados de las seis glaciaciones identificadas por Meglioli para Patagonia meridional y Tierra del Fuego (1992, p. 128 con modificaciones). Los números del 1 al 86 indican la localización de los muestreos de grava realizados por Meglioli para el análisis de anillos de meteorización.

8.265 a 7.490 AP, cuando el ascenso del nivel del mar global alcazó el nivel de ascenso isostático y condujo al inicio de la formación del estrecho (McCulloch \& Morello, 2009).

Considerando el mapa de los límites aproximados de las glaciaciones que presenta Meglioli intentamos establecer una correlación tentativa entre la localización de los muestreos de rocas por nosotros realizados (Fig. 2) y las diferentes glaciaciones. Así, las muestras tomadas en bahía Posesión se corresponderían con la glaciación Punta Delgada, en tanto que las muestras recolectadas en punta Delgada, bahía Santiago y San Gregorio representarían a la glaciación Primera Angostura. Por último, el muestreo realizado en bahía Laredo sería un ejemplo de la glaciación Segunda Angostura.

Si bien la glaciación Sierra de los Frailes fue la que alcanzó el límite más oriental en Patagonia continental $e$ insular, entendemos que no se encuentra representada en la costa del estrecho de Magallanes por la superposición de las glaciaciones subsiguientes. La situación contraria se presenta hacia el interior del CVPA, donde la mayoría de los muestreos de rocas realizados se corresponderían con los depósitos de drift de Sierra de los Frailes. Solamente los muestreos de la zona meridional de Pali Aike, en la Estancia Cóndor-Sección Monte Aymond podrían ser asignados a la glaciación Cabo Vírgenes (Charlin, 2009), aunque no contamos con los elementos necesarios para corroborar este supuesto. Por otro lado, si consideramos 


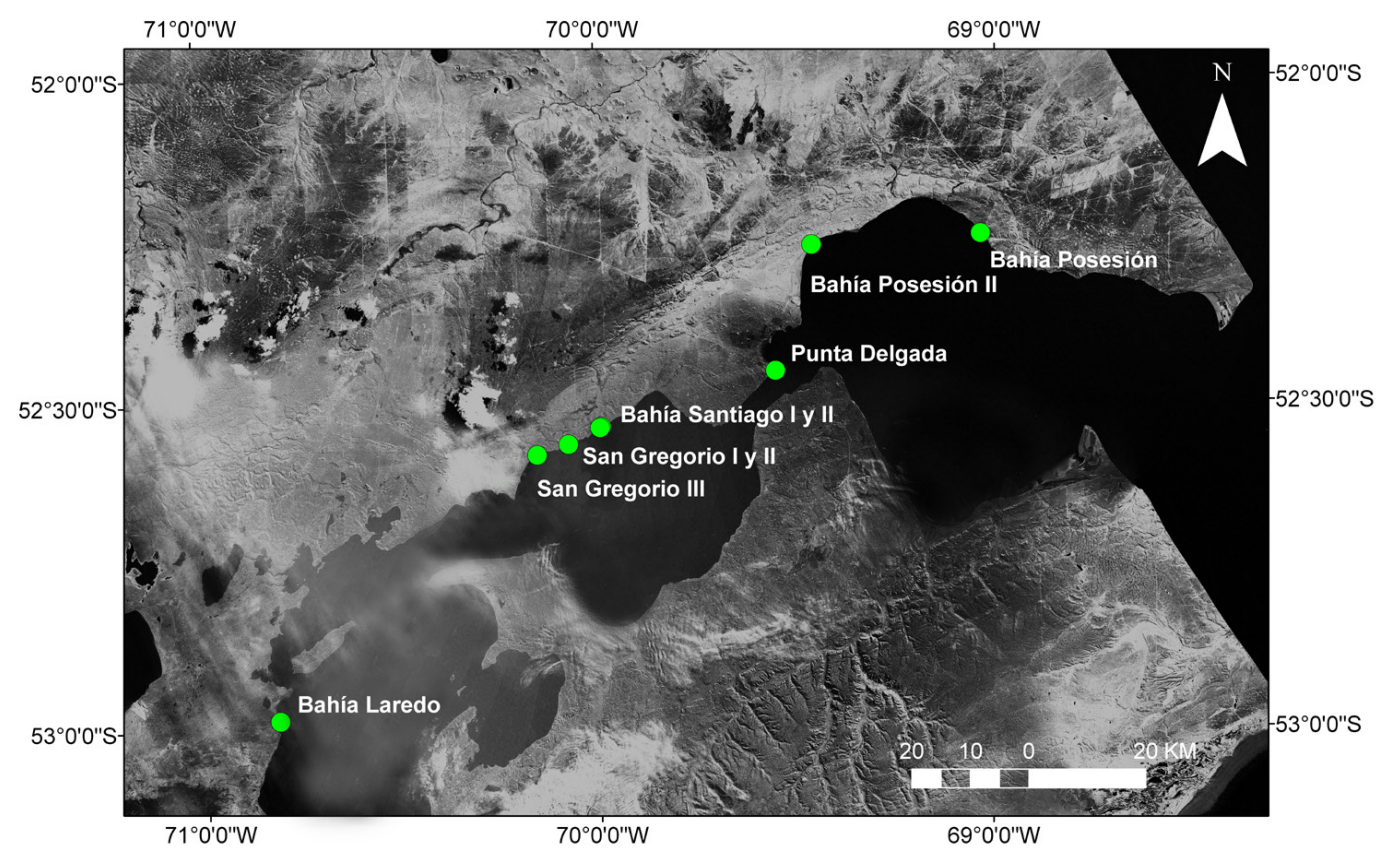

Fig. 2. Localización de los muestreos de roca realizados a lo largo de la costa del estrecho de Magallanes.

los relevamientos de materias primas líticas realizados por otros investigadores, contamos con información sobre la disponibilidad de rocas en el extremo oriental del estrecho de Magallanes, en el área de cabo Vírgenes (L'Heureux \& Franco, 2002) y punta Dungeness (Massone, 1979, 1984), y más hacia el oeste, en bahía Laredo (Prieto, 1988). Mientras el área de cabo Vírgenes y punta Dungeness se correspondería con los depósitos de drift de la glaciación Cabo Vírgenes, bahía Laredo se vincularía con la glaciación Segunda Angostura.

A partir de la información geológica del área que acabamos de sintetizar esperamos encontrar diferencias en la oferta de rocas entre el CVPA y la costa del estrecho de Magallanes, dadas las distintas glaciaciones que afectaron ambos espacios. Asimismo, esperamos una mayor accesibilidad a las fuentes en este último caso, considerando la mayor exposición y continuidad de los depósitos, y por consiguiente una reducción de los costos de aprovisionamiento.

\section{ANTECEDENTES ARQUEOLÓGICOS}

Son numerosos los trabajos arqueológicos efectuados a lo largo de la costa nororiental del estrecho de Magallanes.
Las primeras ocupaciones humanas registradas en este sector del espacio fueron datadas en ca. 3.700 años AP en Cañadón Cóndor (Bird, 1938; Massone, 1979) y Bahía Munición 3 (Laming-Emperaire, 1968). Las mismas se vuelven más frecuentes en los últimos 1.500 años, especialmente en momentos históricos (Martinic, 1984a, 1995; Massone, 1979, 1983, 1984; Prieto, 1988).

Desde las primeras ocupaciones existen evidencias de la explotación del litoral por grupos cazadores-recolectores con una dieta principalmente basada en recursos terrestres (Bird, 1938; Laming-Emperaire, 1965, 1968). Sin embargo, la información publicada sobre la tecnología lítica es muy escasa. En Bahía Munición 3 sólo sabemos que los artefactos de los niveles inferiores son pocos en comparación con aquellos recuperados en los niveles superiores (Laming-Emperaire, 1965), y no tenemos ninguna información sobre las materias primas explotadas ni sobre la tecnología lítica de Cañadón Cóndor (Bird, 1938).

Laming-Emperaire (1968, p. 91) considera a los sitios localizados a lo largo del estrecho de Magallanes, como Bahía Munición 3, como campamentos ocasionales invernales de cazadores 
terrestres.

Posteriormente a estos estudios pioneros, los relevamientos efectuados por Massone (1979, 1983, 1984) entre punta Dungeness (52 $21^{\circ} \mathrm{S}$ $68^{\circ} 26^{\prime} \mathrm{W}$ ) y San Gregorio (52 $38^{\circ} \mathrm{S} 70^{\circ} 11^{\prime} \mathrm{W}$ ) detectaron múltiples sitios arqueológicos, la mayoría en superficie y algunos en estratigrafía, siendo gran parte de ellos ocupaciones históricas. En la localidad San Gregorio se registran ocupaciones desde los ca. 2.800 AP (San Gregorio 2) hasta el siglo XIX (San Gregorio 4) (Massone, 1979, 1984). En bahía Posesión los fechados radiocarbónicos se extienden desde ca. 2.000 a 500 AP en Posesión 3 (Massone, 1979). En la localidad Punta Dungeness el fechado más antiguo es de ca. 1.600 AP (Punta Dungeness 2), registrándose ocupaciones indígenas (Punta Dungeness 5) e hispánicas del siglo XVI (Punta Dungeness 2 y 7) (Massone, 1979, 1983, 1984).

De acuerdo con el estudio de las materias primas líticas, en todos los sitios de superficie predominan las rocas silíceas, con porcentajes entre 57 y $82 \%$ del total de artefactos, excepto en Punta Dungeness 3, en donde el basalto es el más abundante (48\%, Massone, 1979). Esta materia prima se encuentra en segundo lugar en el resto de los contextos arqueológicos superficiales (Massone, 1979).

En Posesión 3, donde se excavaron $16 \mathrm{~m}^{2}$, la distribución de materias primas líticas muestra un patrón diferencial, que se mantiene en todos los niveles: la lutita es la más abundante (70\%), seguida por el material silíceo (28\%) y por último el basalto (2\%). Por el contrario, en Punta Dungeness 2 (37 $\mathrm{m}^{2}$ excavados) se sigue el mismo patrón que en los sitios superficiales (material silíceo en primer lugar, seguido por el basalto).

Estos estudios señalan la disponibilidad de rocas aptas para la talla, especialmente lutita silicificada y basalto, en los depósitos fluvioglaciares erosionados, como así también en las antiguas bermas de punta Dungeness (Massone, 1979, 1984). En base a la información petrográfica obtenida mediante la identificación microscópica de cortes delgados debemos considerar a ambos tipos de rocas (en los casos de color negro) como RGFO.

Massone (1979) señala que la ocupación de gran parte del sector costero, tanto de los altos acantilados como de las terrazas litorales, fue penecontemporánea y recurrente. El sector central del litoral, entre San Gregorio y Posesión, se destaca por la abundancia de sitios, siendo los sectores costeros más orientales y occidentales posiblemente de uso marginal (Massone, 1984).

Por su parte, Ortiz Troncoso (1972) señala que la costa del estrecho de Magallanes habría funcionado como proveedora de buena materia prima para la manufactura de artefactos, así como también de espacios de caza y de recolección de recursos marinos. Dicho autor se ocupa de presentar el inventario descriptivo de colecciones arqueológicas producto de recolecciones superficiales por particulares, ingresadas al Museo de la Patagonia en 1969. En particular nos interesa el material lítico de bahía Posesión, donado por el Sr. Donald Black y alojado actualmente en el Museo Regional de Magallanes (obs. pers.). Entre los materiales (percutores, bolas, bifaces, etc.) se destacan en abundancia las puntas de proyectil pedunculadas $(n=170)$ y los raspadores $(n=101)$. Con respecto a las primeras nos interesa destacar que se encuentran manufacturadas en basalto (Ortiz Troncoso 1972, p. 58, entiéndase como RGFO) y han estado frecuentemente sujetas a procesos de reutilización y reciclaje. Los raspadores, por su parte, son de tamaño pequeño y se encuentran manufacturados predominantemente en rocas silíceas y madera fósil (Ortiz Troncoso, 1972, p. 60).

Hacia la zona occidental del estrecho de Magallanes, en bahía Shoal, como producto de un trabajo de rescate arqueológico debido a la construcción del gasoducto Cabo Negro-Kimiri Aike se detectaron seis concentraciones de materiales líticos superficiales en zonas erosionadas sobre la segunda terraza costera de la bahía (Constantinescu et al. 1999). Sólo se recuperó una microlasca de basalto en estratigrafía. Los restos óseos son escasos debido a la mala conservación. Lamentablemente la mayoría de las materias primas utilizadas para la manufactura de instrumentos son indeterminadas (41\%). Entre las rocas identificadas predomina la obsidiana verde (19\%), seguida por la calcedonia y el basalto (ambos 17\%). Al igual que en casos previos, el basalto debe ser entendido como una RGFO.

Según Constantinescu y coautores (1999), el predominio de la obsidiana verde en los artefactos sugiere la implementación de mecanismos de 
aprovisionamiento que implicaron el intercambio con grupos canoeros. En base a la presencia de ésta materia prima y de bolas con surco ecuatorial, los materiales fueron asignados a momentos tardíos de ocupación del área (en correlación con los períodos IV y V definidos por J. Bird).

Como parte del mismo trabajo de rescate, en la ribera norte del río Pescado se realizaron recolecciones de superficie y cinco sondeos (sólo uno con hallazgos arqueológicos) en un extenso paradero de utilización recurrente denominado Kon Aiken 1 (Constantinescu et al. 1999). Entre las materias primas utilizadas para la confección de instrumentos se destaca el basalto (29\%), seguido por la obsidiana verde (12\%) y la calcedonia (6\%). A pesar del saqueo y perturbación antrópica del sitio, en conjunto los materiales muestran alta diversidad funcional y de materias primas líticas.

Hacia el sur, en Bahía Laredo se registraron siete yacimientos arqueológicos en el sector norte de la bahía (Prieto, 1988). BL1A es el único sitio que cuenta con un fechado radiocarbónico de $1.540 \pm 45$ años AP, y otros sitios del área muestran evidencias de ocupaciones históricas, dadas por la presencia de lozas del siglo XIX (BL1) y clavos de forja (BL5, Prieto, 1988). Prieto (1988) señala que en L1A los instrumentos más grandes, como raederas y cuchillos, fueron confeccionados en materias primas locales, como lutita, toba y riolita, que se encuentran disponibles en las playas de cantos de la bahía. En L1CE se destaca la presencia de lascas y microlascas de obsidiana verde y lajas de lutita de filos muy cortantes (pero de corta duración debido a la fácil exfoliación), materia prima disponible a los pies del cabo (Prieto, 1988 , p. 120). Por su parte, en BL4 se registra una gran dispersión de fragmentos de gabro producto del trabajo en la confección de bolas. Con respecto a la fauna, en la mayoría de los sitios se recuperaron restos de diferentes tipos de moluscos, mamíferos marinos y terrestres, aves y roedores. $\mathrm{Si}$ bien los restos arqueofaunísticos sugieren una dieta basada principalmente en recursos costeros, Bahía Laredo es considerado como el sitio más austral de cazadores-recolectores terrestres (Martinic, 1984b, Prieto, 1988). Según Prieto (1988), la presencia de puntas de proyectil tipo IV y V, la ausencia de arpones y la información histórica que señala al cabo Negro como un paradero frecuente de los
Aonikenk y Guaicurúes sustentan esta hipótesis (Prieto, 1988).

Con respecto a los sitios arqueológicos estudiados en cabo Vírgenes, si bien se localizan sobre la costa atlántica argentina, este espacio habría sido afectado por el lóbulo glaciar del estrecho de Magallanes, por lo cual, como señalamos anteriormente, las materias primas líticas alli disponibles habrían sido el resultado de la glaciación Cabo Vírgenes (Meglioli, 1992). Aquí solo nos interesa señalar que en el sitio Cabo Vírgenes 6 (CV6), fechado en ca. 1.200 años $\mathrm{AP}$, las materias primas más representadas entre los artefactos son el basalto con fenocristales y la dacita (L'Heureux \& Franco, 2002). La calcedonia, el jaspe, las rocas silíceas y la obsidiana verde son minoritarias (L'Heureux \& Franco, 2002). L'Heureux y Franco (2002) señalan que el basalto con fenocristales no se encuentra disponible en las proximidades del sitio y sugieren su procedencia de los depósitos fluvioglaciares de la costa central del estrecho de Magallanes. Posteriormente se detectó su disponibilidad en el área costera de cañadón Gap, aproximadamente a $20 \mathrm{~km}$ hacia el norte de cabo Vírgenes y se consideró a dicha materia prima como una RGFO en base a los análisis en curso (Borrero et al. 2008, p. 216). Actualmente sabemos que estas rocas se encuentran disponibles en las lagunas del interfluvio Gallegos-Chico y en diferentes loci a lo largo del valle del río Gallegos (Charlin, 2009; Charlin \& D'Orazio, 2010; Charlin \& Pallo, 2013). La presencia de fenocristales sugiere que se trata de la dacita vítrea negra de muy buena calidad para la talla, denominada RGFO tipo Potrok Aike (Charlin \& Pallo, 2013) por su mayor abundancia en esta laguna, y cuyas fuentes de procedencia fueron identificadas mediante análisis geoquímicos en dicha laguna, en Palermo Aike y en Punta Loyola (Charlin \& D'Orazio, 2010). Dichas rocas presentan entre el 10 y el $5 \%$ del volumen de fenocristales de plagioclasa de andesina-labradorita y más raramente de fenocristales de clinopiroxeno, ortopiroxeno y óxidos de $\mathrm{Fe}-\mathrm{Ti}$ (Charlin \& D’Orazio, 2010).

La presencia de lascas primarias $y$ secundarias, de talones corticales y de corteza en los artefactos de CV6 sugiere la introducción de nódulos de RGFO al sitio (basalto con fenocristales en términos de L'Heureux \& Franco, 2002). La 
recuperación de puntas de proyectil, preformas de artefactos bifaciales, lascas de reducción bifacial y el elevado porcentaje de talones preparados indica la manufactura de estos instrumentos en el sitio y una mayor inversión de energía en su confección (L'Heureux \& Franco, 2002). Por el contrario, la dacita está disponible en alta frecuencia en la costa atlántica y fue aprovechada de modo expeditivo (Borrero et al. 2008, L'Heureux \& Franco, 2002).

Por su parte, el jaspe, la calcedonia, las rocas silíceas y la obsidiana verde se presentan en bajos porcentajes (inferiores al 1.3\%), sus tamaños son pequeños (entre 5.1-15 mm), carecen de corteza y los talones son lisos o diedros. Estos patrones son entendidos como el resultado de la introducción al sitio de núcleos o de instrumentos ya formatizados (L'Heureux \& Franco, 2002). Considerando la información arqueofaunística, que muestra el predominio de cormoranes y cachorros de lobos marinos, el sitio ha sido interpretado como el resultado de la ocupación de cazadores-recolectores terrestres en el verano austral (noviembre-febrero), coincidiendo con la temporada reproductiva de los lobos marinos (L'Heureux \& Franco, 2002). Sin embargo, revisiones recientes del material faunístico no permiten sostener la estacionalidad en la ocupación de CV6 (ver discusión en Borella, 2010; Borella \& L'Heureux, 2010; Borella et al. 2014; Belardi et al. 2011).

En base a las evidencias de escasa presencia humana en este sector del espacio, se sostiene que el mismo habría sido utilizado de modo marginal en comparación con sitios del interior del CVPA (como Orejas de Burro 1 y Cóndor 1) y de la costa central del estrecho de Magallanes (Barberena et al. 2004; Barberena \& Borrero, 2010; Borrero et al. 2008; L'Heureux \& Franco, 2002; Belardi et al. 2011)

Nuestros estudios previos en la porción argentina del CVPA, particularmente en relación con el grado de reducción de los artefactos, sugirieron que la costa norte del estrecho de Magallanes habría funcionado como una fuente de aprovisionamiento lítico de importancia (Borrero et al. 2009; Charlin, 2007, 2009; Charlin \& Barberena, 2011).

En el caso particular de las RGFO tipo Potrok Aike (Charlin \& Pallo, 2013) y de las calcedonias coloreadas, estudios recientes mostraron que estas rocas se encuentran disponibles en mayor abundancia en las lagunas localizadas en el interfluvio río Gallegos-río Chico, en comparación con las fuentes potenciales de aprovisionamiento registradas en el valle del río Gallegos. Sin embargo, la disponibilidad de estas rocas en el estrecho de Magallanes continuaba siendo un interrogante, ya que más allá de lo señalado por Massone (1984) y Prieto (1988), no se contaba con información de primera mano sobre las variedades de rocas existentes en los depósitos costeros.

\section{RELEVAMIENTO DE CAMPO: METODOLOGÍA}

En base a los antecedentes geológicos y arqueológicos señalados surgió la necesidad de muestrear la costa nororiental del estrecho de Magallanes para evaluar la disponibilidad de recursos líticos en comparación con el CVPA ( $n=77$ loci muestreados). Así, se realizaron nueve muestreos de rocas en los depósitos costeros entre bahía Posesión y bahía Laredo. Los mismos fueron pequeños, en tanto se buscó cubrir la mayor extensión posible de terreno, en un intento por registrar la existencia de variaciones a lo largo de la costa.

Para evaluar la disponibilidad de materias primas líticas se siguió la metodología propuesta por Franco y Borrero (1999). Así, la recolección de materias primas se realizó siguiendo una unidad de tiempo establecida. El criterio de selección que guió la recolección fue la aptitud de las rocas para la talla (de acuerdo con las características texturales observadas macroscópicamente) y la representación de la variabilidad presente. En este punto es necesario señalar que las recolecciones de rocas realizadas con esta metodología no pretenden ser una muestra representativa de la diversidad geológica del área, sino una aproximación a la variabilidad en la disponibilidad de rocas aptas para la talla. En cada una de las rocas recolectadas se midió su tamaño de acuerdo con tres ejes de longitud (Krumbein, 1941 en Scasso \& Limarino, 1997): eje mayor (a), eje intermedio (b) y eje menor (c). Posteriormente, a partir de los tres ejes se calculó la media geométrica como medida de tamaño (Jungers et al. 1995).

La identificación petrográfica comprendió el 
trabajo en dos escalas complementarias: por un lado, la determinación megascópica mediante la observación del interior de la roca (fractura fresca) siguiendo los criterios expuestos en Charlin (2009, Tabla 4.VII) y por el otro, la determinación microscópica a través de cortes delgados de roca. Con tal fin, se seleccionaron las variedades de rocas más representativas de los diferentes muestreos o casos particulares siguiendo objetivos puntuales (tales como la determinación petrográfica de las RGFO).

En este punto, queremos realizar algunas aclaraciones con respecto a la identificación de las rocas y las categorías de clasificación utilizadas. Existen casos en los que no fue posible realizar una determinación del tipo petrográfico a ojo desnudo, por consiguiente esos ejemplares fueron clasificados genéricamente como vulcanitas, sedimentitas o metamorfitas. En el caso de tratarse de rocas sedimentarias de grano fino (tamaño limo-arcilla), fueron clasificadas como pelitas.

La identificación del tipo de roca a ojo desnudo también fue dificultosa en aquellas rocas sometidas a procesos de alteración química (oxidación e infiltración de manganeso) y física (relleno de las fisuras de la roca con material secundario). En estos casos, dado que las superficies alteradas o rellenas canalizan la fractura, no es posible observar una fractura fresca que no se encuentre meteorizada. Estas rocas han sido clasificadas como alteradas o, cuando fue posible determinar su génesis, se las clasificó como vulcanitas, sedimentitas o metamorfitas alteradas. En las instancias en las que no fue clara la diferenciación de tipos petrográficos sin un análisis microscópico, como sucedió en algunos casos con rocas volcánicas básicas, como basaltos, basandesitas y andesitas, las mismas fueron clasificadas como vulcanitas básicas (también denominadas volcanitas intermedias-básicas sensu Alberti \& Fernández, 2014). Lo mismo para las vulcanitas ácidas (como las riolitas y traquitas).

Con respecto a la determinación de la calidad para la talla, se siguieron los criterios de Aragón y Franco (1997) sobre la textura de la pasta/matriz y el contenido de fenocristales $\mathrm{u}$ otras heterogeneidades, a los cuales se agregaron consideraciones tales como la presencia de foliación y el tipo de fractura de la roca. Las categorías diferenciadas en una escala ordinal fueron: mala, regular, buena, muy buena y excelente.
La estrategia de muestreo que hemos delineado nos permite evaluar el rendimiento relativo de las diferentes fuentes potenciales de aprovisionamiento a partir de la cantidad, calidad y tamaño de los nódulos recogidos por unidad de tiempo. En este sentido, consideramos de importancia lograr un conocimiento aproximado de los costos de búsqueda, aprovisionamiento y procesamiento de las materias primas, ya que las estrategias de aprovisionamiento y utilización de los recursos líticos se encuentran en relación directa con los costos de obtención de las mismas (Franco, 1998; Haury, 1995; Hayden, 1989, entre otros).

Finalmente, cabe señalar que las muestras de materias primas recolectadas (excepto las que han sido seleccionadas para cortes delgados) se encuentran almacenadas en el Centro de Estudios del Hombre Austral (Instituto de la Patagonia, Universidad de Magallanes, Chile).

En la Tabla 2 se presentan las coordenadas geográficas, la relación personas/tiempo $(\mathrm{P} / \mathrm{t})$ en la toma de las muestras, el total de rocas recolectadas (n) y algunas observaciones de campo para cada uno de los muestreos realizados.

Cabe señalar que en algunos espacios se tomaron muestras en cotas altas y bajas ya que se observaron diferencias en el tamaño de los nódulos disponibles. En otros sectores, por ejemplo en Bahía Posesión II, las rocas de tamaño adecuado para la talla a mano alzada solamente estaban presentes en las cotas altas, lo cual es acorde con la acción diferencial de los procesos erosivos (como las mareas) según el nivel de la playa. Asimismo se registran diferencias en la forma de los nódulos (sensu Zingg, 1935 en Scasso \& Limarino, 1997) según las cotas debido a los mismos factores: la forma de las rocas tiende a tabular u oblada a mayor efecto erosivo de las mareas. Estas diferencias se observaron claramente en Punta Delgada. Finalmente, queremos señalar que en Bahía Laredo se encuentran disponibles bloques de rocas, probablemente de origen volcánico, que no fueron muestreados ya que no se observaron evidencias de su explotación por las poblaciones pasadas.

\section{RESULTADOS}

Análisis de cortes delgados de roca

18 muestras naturales fueron determinadas 
Tabla 2. Muestreos de rocas realizados en la costa nororiental del estrecho de Magallanes.

\begin{tabular}{lllll}
\hline \multicolumn{1}{c}{ Muestreo } & \multicolumn{1}{c}{ Coordenadas } & Observaciones & P/t & $\mathrm{n}$ \\
\hline Bahía Posesión I & $52^{\circ} 14^{\prime} 50.1^{\prime \prime} 69^{\circ} 01^{\prime} 55.7^{\prime \prime}$ & Margen oriental & $1 \mathrm{px} 10 \mathrm{~m}^{*}$ & 59 \\
Bahía Posesión II & $52^{\circ} 15^{\prime} 51.9^{\prime \prime} 69^{\circ} 27^{\prime} 22^{\prime \prime}$ & Margen occidental, cotas altas & $1 \mathrm{px} 8 \mathrm{~m}$ & 35 \\
Punta Delgada & $52^{\circ} 27^{\prime} 27.4^{\prime \prime} 69^{\circ} 32^{\prime} 52.3^{\prime \prime}$ & Cotas altas & $1 \mathrm{px} 5 \mathrm{~m}$ & 20 \\
Bahía Santiago I & $52^{\circ} 32^{\prime} 29.2^{\prime \prime} 69^{\circ} 59^{\prime} 18.2^{\prime \prime}$ & Cotas altas & $1 \mathrm{px} 5 \mathrm{~m}$ & 35 \\
Bahía Santiago II & $52^{\circ} 32^{\prime} 34.2^{\prime \prime} 69^{\circ} 59^{\prime} 28.5^{\prime \prime}$ & En extremo W de bahía & $1 \mathrm{px} 5 \mathrm{~m}$ & 27 \\
San Gregorio I & $52^{\circ} 34^{\prime} 4.4^{\prime \prime} 70^{\circ} 4^{\prime} 17.7^{\prime \prime}$ & Cotas bajas & $1 \mathrm{px} 5 \mathrm{~m}$ & 13 \\
San Gregorio II & $52^{\circ} 34^{\prime} 4.4^{\prime \prime} 70^{\circ} 4^{\prime} 17.7^{\prime \prime}$ & Cotas altas & $1 \mathrm{px} 5 \mathrm{~m}$ & 17 \\
San Gregorio III & $52^{\circ} 35^{\prime} 1.3^{\prime \prime} 70^{\circ} 9^{\prime} 2.5^{\prime \prime}$ & Cotas altas, hacia el W & $1 \mathrm{px} 5 \mathrm{~m}$ & 31 \\
Bahía Laredo & $52^{\circ} 59^{\prime} 8^{\prime \prime} 70^{\circ} 48^{\prime} 52.6^{\prime \prime}$ & Extremo sur & $1 \mathrm{px} 5 \mathrm{~m}$ & 32 \\
\hline
\end{tabular}

* 1px10m= cantidad de personas y minutos de recolección.

al microscopio mediante la observación de cortes delgados de roca, nueve de los cuales corresponden a RGFO (Tabla 3). Megascópicamente ninguna de ellas guarda semejanzas con la RGFO tipo Potrok Aike (Charlin \& Pallo, 2013), lo cual fue corroborado mediante la identificación microscópica. Esta variedad de dacita vítrea de muy buena calidad para la talla es la más explotada en los sitios arqueológicos del CVPA localizados en Argentina y se encuentra disponible en los depósitos secundarios de Potrok Aike, Palermo Aike y Punta Loyola, según los análisis geoquímicos de roca total y elementos traza realizados con anterioridad (Charlin \& D'Orazio, 2010). Los relevamientos efectuados recientemente en el interfluvio Gallegos-Chico han permitido identificar nuevas fuentes potenciales de aprovisionamiento de esta roca (Charlin \& Pallo, 2013).

La mayoría de los nódulos de RGFO representativos de las variedades disponibles en la costa del estrecho de Magallanes fueron determinados como rocas pelíticas de grano fino (limo-arcilla) con diferentes grados de metamorfismo (en general bajo), clasificadas como pizarras. En algunos casos estas rocas muestran señales de termometamorfismo (metamorfismo de contacto). Solamente se identificaron tres variedades volcánicas, todas ellas distintas a las dacitas tipo Potrok Aike: basalto primitivo posiblemente relacionado con el vulcanismo del CVPA, metabasalto -basalto recristalizado por acción hidrotermal- y traquita. Por consiguiente, las RGFO disponibles en el estrecho de Magallanes corresponden a variedades diferentes a las registradas en los muestreos realizados hacia el interior del CVPA.

\section{Abundancia}

En la Tabla 4, siguiendo las determinaciones realizadas mediante cortes delgados, las pizarras de color negro se encuentran clasificadas como RGFO. Lo que se denomina pizarra corresponde a rocas de otros colores.

Las RGFO y las dacitas son las rocas más abundantes aproximadamente en la mitad de los muestreos (5/9), alternando entre el primer y segundo lugar (Tabla 3). En Bahía Posesión II, luego de las RGFO se encuentran las pizarras, al igual que en Punta Delgada, donde además se suman las diabasas. En Bahía Laredo las vulcanitas básicas son las que predominan, ubicándose las RGFO en segundo lugar. San Gregorio II ofrece un caso particular, en el cual tanto las dacitas como las RGFO se encuentran desplazadas de los primeros lugares. Aquí el basalto es el más abundante, seguido por la diabasa, aunque el tamaño de la muestra es pequeño para sostener la tendencia.

A pesar de las variaciones en abundancia, las RGFO y las tonalitas (éstas escasas) son los tipos de roca que se encuentran representados en todos los muestreos. Algo similar ocurre con las 
Tabla 3. Determinación microscópica de cortes delgados de roca.

\begin{tabular}{|c|c|c|c|}
\hline Muestreo & $\mathrm{N}^{\circ}$ invent & Determinación microscópica & $\begin{array}{l}\text { Clasificación } \\
\text { megascópica }\end{array}$ \\
\hline Bahía Posesión & BPI 52 & Pizarra & RGFO \\
\hline Bahía Posesión & BPI 14 & Pizarra & RGFO \\
\hline Bahía Posesión & BPI 50 & Diabasa uralizada & \\
\hline Bahía Posesión & BPI 24 & Traquita & RGFO \\
\hline Punta Delgada & PD 20 & Diabasa & \\
\hline Punta Delgada & PD 10 & Diabasa uralizada & \\
\hline Punta Delgada & PD 13 & Vulcanita alterada & \\
\hline Bahía Santiago I & BSI 17 & Vulcanita alterada & \\
\hline Bahía Santiago II & BSII 24 & Pizarra & RGFO \\
\hline Bahía Santiago II & BSII 18 & Metabasalto & RGFO \\
\hline Bahía Santiago II & BSII 23 & Fangolita arenosa & \\
\hline San Gregorio I & SGI 6 & Andesita & RGFO \\
\hline San Gregorio II & SGII 12 & Pizarra & RGFO \\
\hline San Gregorio II & SGII 8 & Dacita & \\
\hline San Gregorio III & SGIII 2 & Dacita & \\
\hline Bahía Laredo & BL 11 & Sedimentita alterada & \\
\hline Bahía Laredo & BL 29 & Basalto primitivo & RGFO \\
\hline Bahía Laredo & BL 19 & Pizarra & RGFO \\
\hline
\end{tabular}

dacitas, que solo están ausentes en Bahía Laredo. Las traquitas solo se encuentran representadas en los muestreos más orientales (Bahía Posesión I y II). Por su parte, las rocas y minerales que únicamente se encuentran presentes en un solo muestreo son el jaspe (con impurezas), la cuarcita y el granito. El resto de las materias primas muestran variaciones entre los loci.

Con respecto a las RFGO en particular, el $86 \%$ $(\mathrm{n}=51)$ corresponde a variedades metamórficas, de las cuales el $95 \%(n=48)$ han sido identificadas como pizarras mediante la determinación microscópica de cortes delgados, que sirvieron como muestras comparativas de referencia para la clasificación del resto de los ejemplares (Tabla 5). Solo tres muestras corresponden a metabasalto y han sido recuperadas en Bahía Posesión II, Bahía Santiago II y San Gregorio I. El ejemplar que fue determinado al microscopio es el procedente de Bahía Santiago II y fue descripto como basalto recristalizado por metamorfismo hidrotermal.

El $14 \%(n=8)$ restante de las RGFO son variedades volcánicas, identificadas como traquita $(n=4)$ y basalto $(n=4)$. Las primeras han sido recuperadas en Bahía Posesión I, donde también se registra un ejemplar de basalto. El resto de los basaltos proceden de San Gregorio I y II y Bahía Laredo. El ejemplar procedente de este último locus fue determinado al microscopio como un basalto primitivo posiblemente relacionado con el vulcanismo de Pali Aike. Cabe señalar que ninguna de estas variedades se corresponde con el tipo Potrok Aike.

Si evaluamos la riqueza de tipos de roca por muestreo (Tabla 3), se observa un incremento de oeste a este, aunque no sigue un patrón netamente lineal. En el recuento de clases no se consideraron aquellas indeterminadas, tales como vulcanitas o sedimentitas indeterminadas o alteradas, como así tampoco se incluyó en el conteo a las categorías de vulcanita ácida o básica cuando esta clase de roca se encontraba representada por algún tipo específico en el propio muestreo, como por ejemplo granito en el primer caso o basalto en el segundo. Las RGFO fueron consideradas como un único tipo, a pesar de las variedades que incluye.

A pesar de la tendencia espacial observada, si evaluamos la correlación entre la riqueza y el 
Tabla 4. Frecuencia de tipos de roca por muestreo.

\begin{tabular}{|c|c|c|c|c|c|c|c|c|c|c|c|c|}
\hline Muestreo & $\mathrm{Dac}$ & RGFO & VulBás & Andes & Diab & Tonal & Traq & $\mathrm{Cu}$ & $\mathrm{Pel}$ & $\mathrm{Piz}$ & $\mathrm{Ft}$ & Bas \\
\hline Bahía Posesión I & 19 & 11 & 4 & 3 & 2 & 4 & 6 & 1 & 0 & 2 & 2 & 0 \\
\hline Bahía Posesión II & 3 & 7 & 0 & 4 & 3 & 1 & 6 & 1 & 1 & 1 & 4 & 0 \\
\hline Punta Delgada & 2 & 7 & 0 & 0 & 3 & 1 & 0 & 2 & 0 & 3 & 0 & 0 \\
\hline Bahía Santiago I & 16 & 6 & 0 & 1 & 1 & 1 & 0 & 1 & 0 & 0 & 1 & 1 \\
\hline Bahía Santiago II & 13 & 6 & 0 & 3 & 0 & 1 & 0 & 1 & 0 & 1 & 0 & 0 \\
\hline San Gregorio 1 & 2 & 2 & 0 & 0 & 3 & 1 & 0 & 0 & 0 & 0 & 0 & 4 \\
\hline San Gregorio ll & 5 & 4 & 2 & 3 & 0 & 1 & 0 & 0 & 1 & 0 & 0 & 0 \\
\hline San Gregorio lll & 14 & 9 & 0 & 0 & 0 & 2 & 0 & 2 & 0 & 2 & 1 & 0 \\
\hline Bahía Laredo & 0 & 7 & 11 & 0 & 2 & 2 & 0 & 1 & 7 & 0 & 0 & 0 \\
\hline Total & 74 & 59 & 17 & 14 & 14 & 14 & 12 & 10 & 9 & 9 & 8 & 5 \\
\hline Muestreo & Dio & Fang & VulÁc & VulAlt & Indet & Jas & Cuar & Gran & SedAl & Vullndet & Total & Riqueza \\
\hline Bahía Posesión I & 2 & 0 & 2 & 1 & 0 & 0 & 0 & 0 & 0 & 0 & 59 & 10 \\
\hline Bahía Posesión II & 0 & 1 & 0 & 1 & 1 & 1 & 0 & 0 & 0 & 0 & 35 & 11 \\
\hline Punta Delgada & 1 & 0 & 0 & 1 & 0 & 0 & 0 & 0 & 0 & 0 & 20 & 7 \\
\hline Bahía Santiago I & 2 & 2 & 1 & 1 & 1 & 0 & 0 & 0 & 0 & 0 & 35 & 11 \\
\hline Bahía Santiago II & 0 & 1 & 1 & 0 & 0 & 0 & 0 & 0 & 0 & 0 & 27 & 7 \\
\hline San Gregorio 1 & 0 & 0 & 0 & 0 & 0 & 0 & 1 & 0 & 0 & 0 & 13 & 6 \\
\hline San Gregorio ll & 0 & 0 & 0 & 0 & 1 & 0 & 0 & 0 & 0 & 0 & 17 & 5 \\
\hline San Gregorio lll & 0 & 0 & 0 & 0 & 0 & 0 & 0 & 0 & 0 & 1 & 31 & 6 \\
\hline Bahía Laredo & 0 & 0 & 0 & 0 & 0 & 0 & 0 & 1 & 1 & 0 & 32 & 7 \\
\hline Total & 5 & 4 & 4 & 4 & 3 & 2 & 1 & 1 & 1 & 1 & 269 & \\
\hline
\end{tabular}

Referencias: Dac: dacita, VulBás: vulcanita básica, Andes: andesita, Diab: diabasa, Tonal: tonalita, Traq: traquita, Cu: cuarzo, Pel: pelita, Piz: pizarra, Ft: ftanita, VulAlt: vulcanita alterada, Dio: diorita, Fang: fangolita, VulÂc: vulcanita ácida, Indet.: indeterminada, Jas: jaspe con impurezas, Bas: basalto, Cuar: cuarcita, Gran: granito, SedAl: sedimentita alterada, Vullndet: vulcanita indeterminada.

Tabla 5. Variedades de RGFO por muestreo.

\begin{tabular}{lccc}
\hline \multicolumn{1}{c}{ Muestreo } & \multicolumn{2}{c}{ RGFO } & Total \\
& metamórfica & volcánica & \\
\hline Bahía Posesión I & 6 & 5 & 11 \\
Bahía Posesión II & 7 & 0 & 7 \\
Punta Delgada & 7 & 0 & 7 \\
Bahía Santiago I & 6 & 0 & 6 \\
Bahía Santiago II & 6 & 0 & 6 \\
San Gregorio l & 1 & 1 & 2 \\
San Gregorio ll & 3 & 1 & 4 \\
San Gregorio lll & 9 & 0 & 9 \\
Bahía Laredo & 6 & 1 & 7 \\
\hline Total & 51 & 8 & 59 \\
\hline
\end{tabular}

tamaño de la muestra, queda demostrado que hay una dependencia entre ambas variables ( $\mathrm{rs}=0.81$ $\mathrm{p}=0.011$ ).

\section{Calidad para la talla}

La mayoría de las rocas recolectadas considerando el total de los muestreos es buena (45\%, $n=120$, Tabla 6). Sin embargo, si tomamos conjuntamente las calidades regulares y malas, más de la mitad $(54 \%, \mathrm{n}=146)$ de las rocas muestreadas son deficientes para la talla. Esto se debe principalmente a tres factores de diferente tipo: 1 . la presencia frecuente de rocas plutónicas y filónicas de grano grueso (como diorita, diabasa, granito), 2. la acción de procesos de alteración química y 
Tabla 6. Frecuencia de rocas por muestreo según su calidad para la talla.

\begin{tabular}{lccccc}
\hline \multicolumn{7}{c}{ Calidad para la talla } \\
\hline Muestreo & muy buena & buena & regular & mala & Total \\
\hline Bahía Posesión I & 1 & 31 & 18 & 9 & 59 \\
Bahía Posesión II & 0 & 17 & 15 & 3 & 35 \\
Punta Delgada & 0 & 5 & 4 & 11 & 20 \\
Bahía Santiago I & 1 & 9 & 22 & 3 & 35 \\
Bahía Santiago II & 0 & 20 & 2 & 5 & 27 \\
San Gregorio l & 0 & 7 & 3 & 3 & 13 \\
San Gregorio ll & 0 & 9 & 8 & 0 & 17 \\
San Gregorio lll & 0 & 9 & 10 & 12 & 31 \\
Bahía Laredo & 1 & 13 & 11 & 7 & 32 \\
\hline Total & 3 & 120 & 93 & 53 & 269 \\
\hline
\end{tabular}

física, como la oxidación, la corrosión, la acción hidrotermal y los efectos tensionales, entre otros, que afectan los planos de fractura, producen fisuras y la disolución y reemplazo de los componentes primarios de la roca, como así también la fusión y recristalización, ${ }^{1}$ y 3 . el porcentaje alto de rocas metamórficas que presentan foliación (pizarras).

En ningún muestreo se registró alguna roca de calidad excelente y solo tres ejemplares resultaron muy buenos, lo cual apunta hacia el bajo rendimiento de las fuentes potenciales de aprovisionamiento del estrecho de Magallanes en rocas adecuadas para la talla.

$\mathrm{Si}$ consideramos la distribución de las calidades de las rocas por muestreo, solamente en los casos de Bahía Posesión I (54\%, n=31) y Bahía Santiago II $(74 \%, n=20)$ predominan las rocas buenas. Por el contrario, en Punta Delgada (55\%, $\mathrm{n}=11)$ y en San Gregorio III $(34 \%, \mathrm{n}=12)$ las rocas más abundantes son de calidad mala, mientras que en Bahía Santiago I se destacan las calidades regulares $(63 \%, n=22)$. Si elaboramos una tabla de contingencia considerando conjuntamente, por un lado, las rocas muy buenas y buenas para la talla y por el otro, las rocas regulares y malas, y agrupamos los muestreos realizados en la misma localidad para evitar así la presencia de frecuencias inferiores a cinco y poder realizar un test de Chi cuadradro, se observa que la calidad de las rocas para la talla es independiente a la localización

1 Todos estos factores de alteración y otros han sido observados mediante la inspección microscópica de los geográfica $\left(\mathrm{x}^{2}=5,7942, \mathrm{gl}=4, \mathrm{p}=0,21506\right)$. Esto nos impide realizar alguna generalización espacial sobre la disponibilidad de rocas de distintas calidades según la localización de los muestreos.

En el caso particular de las RGFO (Tabla 7), la cantidad de rocas de calidades buenas y regulares es casi el mismo (20 y 21 respectivamente). Sin embargo, si consideramos conjuntamente las calidades deficientes (malas y regulares) y adecuadas (buenas y muy buenas) para la talla, predominan las primeras representando el $64 \%(n=38)$ del total de las RGFO muestreadas. Esto se debe principalmente a que la mayoría de las RGFO del estrecho de Magallanes son pizarras, es decir, rocas metamórficas foliadas. Mientras en las variedades volcánicas las cantidades de rocas buenas y regulares/malas son iguales, entre las rocas metamórficas, el $67 \%(n=34)$ corresponde a estas últimas.

Las RGFO regulares y malas predominan en Bahía Posesión II, Punta Delgada, Bahía Santiago I y San Gregorio I y III (Tabla 8).

\section{Tamaños}

Si evaluamos el tamaño medio de los nódulos de roca por muestreo (Tabla 9, Fig. 3), se observa una tendencia de aumento en los tamaños de las rocas de este a oeste, aunque como en el caso de la abundancia no es perfectamente lineal. El análisis de la varianza muestra que

cortes delgados de roca. 
Tabla 7. Frecuencia de RGFO por variedad y tipo de roca según su calidad para la talla.

\begin{tabular}{|c|c|c|c|c|c|c|}
\hline \multirow{2}{*}{$\begin{array}{c}\text { Variedad } \\
\text { RGFO }\end{array}$} & \multirow{2}{*}{$\begin{array}{c}\text { Tipo } \\
\text { de roca }\end{array}$} & \multicolumn{4}{|c|}{ Calidad para la talla } & \multirow{2}{*}{ Tota } \\
\hline & & muy buena & buena & regular & mala & \\
\hline \multirow{2}{*}{ Metamórfica } & Metabasalto & 0 & 2 & 1 & 0 & 3 \\
\hline & Pizarra & 1 & 14 & 18 & 15 & 48 \\
\hline \multirow{2}{*}{ Volcánica } & Basalto & 0 & 2 & 1 & 1 & 4 \\
\hline & Traquita & 0 & 2 & 1 & 1 & 4 \\
\hline \multicolumn{2}{|c|}{ Total } & 1 & 20 & 21 & 17 & 59 \\
\hline
\end{tabular}

Tabla 8. Frecuencia de tipos de RGFO por muestreo según su calidad para la talla.

\begin{tabular}{|c|c|c|c|c|c|c|}
\hline \multirow[b]{2}{*}{ Muestreo } & \multicolumn{6}{|c|}{ Calidad para la talla } \\
\hline & Tipo RGFO & muy buena & buena & regular & mala & Total \\
\hline \multirow{3}{*}{ Bahía Posesión I } & Basalto & 0 & 1 & 0 & 0 & 1 \\
\hline & Pizarra & 0 & 3 & 1 & 2 & 6 \\
\hline & Traquita & 0 & 2 & 1 & 1 & 4 \\
\hline Total Bahía Posesión I & & 0 & 6 & 2 & 3 & 11 \\
\hline \multirow{2}{*}{ Bahía Posesión II } & Metabasalto & 0 & 0 & 1 & 0 & 1 \\
\hline & Pizarra & 0 & 1 & 5 & 0 & 6 \\
\hline Total Bahía Posesión II & & 0 & 1 & 6 & 0 & 7 \\
\hline Punta Delgada & Pizarra & 0 & 1 & 0 & 6 & 7 \\
\hline Total Punta Delgada & & 0 & 1 & 0 & 6 & 7 \\
\hline Bahía Santiago I & Pizarra & 0 & 1 & 4 & 1 & 6 \\
\hline Total Bahía Santiago I & & 0 & 1 & 4 & 1 & 6 \\
\hline \multirow{2}{*}{ Bahía Santiago II } & Metabasalto & 0 & 1 & 0 & 0 & 1 \\
\hline & Pizarra & 0 & 3 & 1 & 1 & 5 \\
\hline Total Bahía Santiago II & & 0 & 4 & 1 & 1 & 6 \\
\hline \multirow{2}{*}{ San Gregorio 1} & Basalto & 0 & 0 & 0 & 1 & 1 \\
\hline & Metabasalto & 0 & 1 & 0 & 0 & 1 \\
\hline Total San Gregorio 1 & & 0 & 1 & 0 & 1 & 2 \\
\hline \multirow[t]{2}{*}{ San Gregorio ll } & Basalto & 0 & 0 & 1 & 0 & 1 \\
\hline & Pizarra & 0 & 1 & 2 & 0 & 3 \\
\hline Total San Gregorio 11 & & 0 & 1 & 3 & 0 & 4 \\
\hline San Gregorio lll & Pizarra & 0 & 2 & 4 & 3 & 9 \\
\hline Total San Gregorio 111 & & 0 & 2 & 4 & 3 & 9 \\
\hline \multirow{2}{*}{ Bahía Laredo } & Basalto & 0 & 1 & 0 & 0 & 1 \\
\hline & Pizarra & 1 & 2 & 1 & 2 & 6 \\
\hline Total Bahía Laredo & & 1 & 3 & 1 & 2 & 7 \\
\hline Total general & & 1 & 20 & 21 & 17 & 59 \\
\hline
\end{tabular}


Tabla 9. Estadística descriptiva del tamaño de las rocas por muestreo.

\begin{tabular}{lccccccccc}
\hline Estadísticos & $\begin{array}{c}\text { Bahía } \\
\text { Posesión } \\
\text { I }\end{array}$ & $\begin{array}{c}\text { Bahía } \\
\text { Posesión II }\end{array}$ & $\begin{array}{c}\text { Punta } \\
\text { Degada }\end{array}$ & $\begin{array}{c}\text { Bahía } \\
\text { Santiago } \\
\text { I }\end{array}$ & $\begin{array}{c}\text { Bahía } \\
\text { Santiago } \\
\text { II }\end{array}$ & $\begin{array}{c}\text { San } \\
\text { Gregorio } \\
\text { I }\end{array}$ & $\begin{array}{c}\text { San } \\
\text { Gregorio } \\
\text { II }\end{array}$ & $\begin{array}{c}\text { San } \\
\text { Gregorio } \\
\text { III }\end{array}$ & $\begin{array}{c}\text { Bahía } \\
\text { Laredo }\end{array}$ \\
\hline $\mathrm{N}$ & 59 & 35 & 20 & 35 & 27 & 13 & 17 & 31 & 32 \\
Mínimo & 33.57 & 21.07 & 26.21 & 34.97 & 33.82 & 49.41 & 38.01 & 33.86 & 46.68 \\
Máximo & 71.28 & 88.57 & 77.81 & 67.37 & 86.02 & 85.58 & 90.83 & 82.97 & 90.44 \\
Media & 52.85 & 55.08 & 57.31 & 50.24 & 53.98 & 69.59 & 62.07 & 53.65 & 71.55 \\
Desvío & & & & & & & & & \\
Estándar & 8.24 & 12.19 & 13.18 & 8.33 & 11.03 & 10.89 & 13.42 & 9.52 & 11.81 \\
Mediana & 53.14 & 54.99 & 57.605 & 48.69 & 54.73 & 71.79 & 65.25 & 53.66 & 72.69 \\
Percentil 25 & 48.24 & 48.49 & 48.3425 & 42.27 & 45.9 & 59.795 & 51.94 & 47.64 & 64.19 \\
Percentil 75 & 56.98 & 60.2 & 69.1775 & 56.95 & 60.6 & 78.55 & 70.155 & 58.19 & 79.4 \\
\hline
\end{tabular}

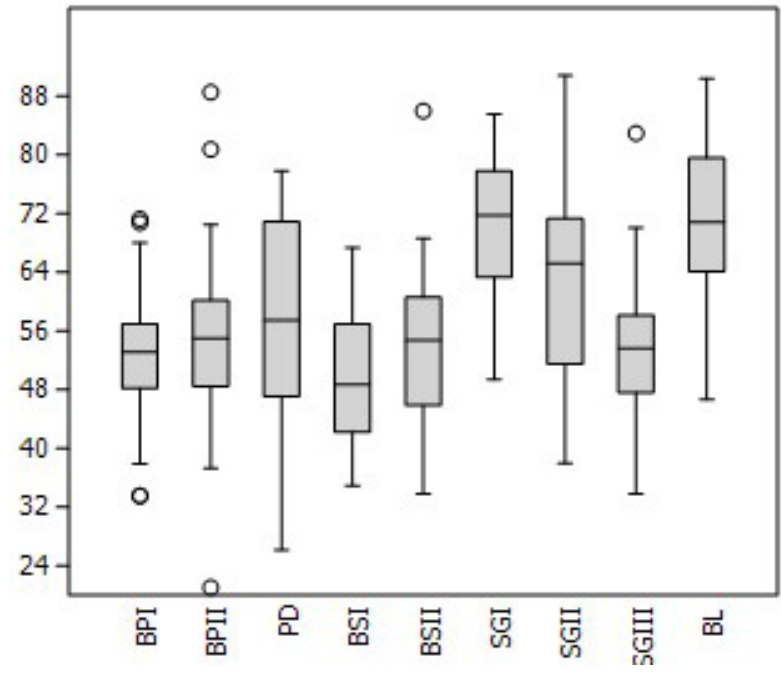

Fig. 3. Gráfico de caja de los tamaños de las rocas por muestreo. Referencias: BPI=Bahía Posesión I, BPII Bahía Posesión II, PD=Punta Delgada, BSI=Bahía Santiago I, BSII= Bahía Santiago II, SGI=San Gregorio I, SGII= San Gregorio II, SGIII= San Gregorio III, BL=Bahía Laredo.

existen diferencias significativas en los tamaños de las rocas disponibles según sector del espacio $(\mathrm{F}=14.06, \mathrm{p}=<0.01)$. La media de tamaño más pequeña se registra en Bahía Santiago I y la más grande en Bahía Laredo. De acuerdo con el desvío estándar, las mayores variaciones se encuentran en San Gregorio II y Punta Delgada.

\section{DISCUSIÓN}

A partir de la información glaciológica regional nuestra expectativa era encontrar diferencias en la oferta de rocas entre sectores del CVPA y la costa del estrecho de Magallanes en relación con las distintas glaciaciones que afectaron ambos espacios. Efectivamente esto se ha corroborado en varios aspectos que se detallan a continuación.

La presencia de RGFO en la totalidad de los muestreos realizados en la costa nororiental del estrecho de Magallanes y su predominio en casi la mitad de los mismos $(4 / 9,44 \%)$ muestra un patrón diferente al registrado en el CVPA, donde estas rocas se encuentran ausentes en aproximadamente la mitad de los muestreos ( $n=39,49 \%)$ y cuando se encuentran disponibles son minoritarias. Si comparamos la distribución de las proporciones de RGFO disponibles en los muestreos de ambos sectores del espacio (Tabla 10) se observa que en el estrecho de Magallanes es posible obtener mayor cantidad de RGFO promedio (0,23 vs. 0,16 en el estrecho y en el CVPA respectivamente). Si bien la proporción máxima de RGFO que es posible obtener en el estrecho de Magallanes y en el CVPA es similar $(0,35$ vs. 0,39$)$-pero acotada a locus puntuales-, las variaciones relativas en la abundancia de RGFO en los distintos sectores de la costa del estrecho y del interior del CVPA marcan notables diferencias: la proporción mínima disponible en el estrecho es de 0,15 RGFO, en tanto que en el CVPA esta se reduce a 0,02. Mientras en la costa es posible obtener en un $50 \%$ de los muestreos entre 20-27\% de RGFO por recolección, en el CVPA en la misma cantidad de casos es posible obtener entre 8 y $22 \%$ de RGFO. De esto se desprende que la variabilidad en la disponibilidad de estas rocas en el 
Tabla 10. Estadística descriptiva de la proporción de RGFO disponibles en los muestreos del estrecho de Magallanes y del CVPA (no se incluyen las ausencias).

\begin{tabular}{lcc}
\hline & E. Magallanes & CVPA \\
\hline $\mathrm{N}$ & 9 & 38 \\
Mínimo & 0,15 & 0,02 \\
Máximo & 0,35 & 0,39 \\
Media & 0,23 & 0,16 \\
Desviación estándar & 0,06 & 0,10 \\
Mediana & 0,22 & 0,14 \\
Percentil 25 & 0,20 & 0,08 \\
Percentil 75 & 0,27 & 0,22 \\
\hline
\end{tabular}

CVPA es mucho mayor, como también lo sugieren los valores de la desviación estándar (ver Fig. 4). Sin embargo, al respecto debemos considerar la diferencia existente en el número de muestreos realizados en ambos sectores (9 vs. 38).

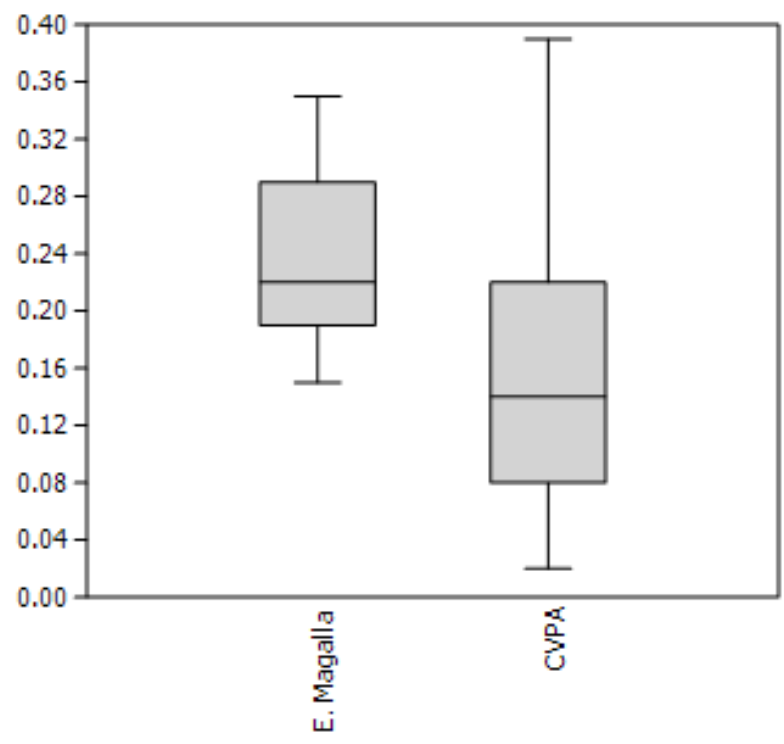

Fig. 4. Gráfico de cajas de la proporción de RGFO disponibles en el estrecho de Magallanes vs. el CVPA.

Con respecto a las fuentes potenciales de aprovisionamiento de RGFO en el CVPA, cabe señalar que al sur del río Chico, donde 31 loci fueron muestreados, estas rocas se encuentran totalmente ausentes.

Otro aspecto diferencial en la disponibilidad

2 Esta dacita (tipo Potrok Aike) es diferente de las dacitas de los volcanes Reclus y Burney, localizados en latitudes del de rocas entre el CVPA y el estrecho de Magallanes que es importante señalar es que las RGFO disponibles en este último sector corresponden generalmente a variedades de roca (principalmente metamórficas) diferentes a las registradas en los muestreos realizados hacia el interior del CVPA, donde predominan las variedades volcánicas a lo largo del valle del río Gallegos y en el interfluvio Gallegos-Chico y las variedades sedimentarias hacia las nacientes del río Gallegos, en la zona conocida localmente como Los Morros, y también en el área del río Turbio (ambas hacia el NW del CVPA, Charlin, 2012; Charlin \& Pallo, 2013; Charlin et al. 2011).

Por otro lado, en la costa del estrecho de Magallanes, en ningún caso se recuperaron ejemplares del tipo Potrok Aike, que es la variedad volcánica más explotada en los sitios arqueológicos del CVPA. Asimismo, tampoco se ha registrado la presencia de calcedonia, que es una materia prima explotada principalmente para la manufactura de raspadores y puntas de proyectil. Esto parecería sugerir que la fuente primaria de ambos tipos de roca se encontraría más al norte de los espacios afectados por el lóbulo glacial del estrecho de Magallanes. Previamente se ha sugerido una similitud geoquímica entre la dacita negra (denominada actualmente tipo Potrok Aike) y las traquidacitas de los volcanes Cay y Maca $\left(\sim 45^{\circ}\right.$ $\left.\mathrm{S} 73^{\circ} \mathrm{W}\right)^{2}$, pero lo más probable es que la fuente primaria de esta roca se encuentre hoy en día erosionada (Charlin \& D'Orazio, 2010).

En referencia a las calidades de las rocas disponibles en las fuentes potenciales de aprovisionamiento del estrecho de Magallanes, en general predominan las rocas regulares $y$ malas, patrón que se repite también en el caso particular de las RGFO. Por consiguiente, aunque estas rocas se encuentren en mayor abundancia en los depósitos costeros que en el CVPA, y que la accesibilidad a los primeros sea de mayor facilidad, sobre todo por su continuidad en el espacio, las deficiencias en la calidad de las rocas para la talla reducen notablemente el rendimiento de las fuentes potenciales de aprovisionamiento del estrecho de Magallanes, incrementando los costos de obtención. Al respecto, la expectativa

CVPA (Charlin \& D'Orazio, 2010). 
que señalamos en un principio con respecto a la reducción de los costos de aprovisionamiento debido a la extensión, continuidad y accesibilidad de los depósitos costeros, no se habría cumplido ya que los costos de obtención se incrementan debido a la baja calidad de las rocas disponibles.

En relación con la información publicada sobre el uso de las materias primas líticas para la manufactura de artefactos en los sitios arqueológicos localizados en la franja litoral del estrecho de Magallanes es necesario que consideremos que la roca denominada lutita por Massone (1979), que predomina por ejemplo en Posesión 3, debe ser entendida como una RGFO metamórfica, dado que las rocas metamórficas foliadas (como es el caso de las pizarras) pueden confundirse fácilmente con rocas pelíticas laminadas (como la lutita) a ojo desnudo. Lo mismo con respecto a las lajas de lutita que Prieto (1988) señala que se encuentran disponibles al pie del cabo Negro y que predominan en los artefactos de L1CE como filos cortantes.

Asimismo, en lo que Massone (1979) denomina "material silíceo" probablemente se están agrupando las dacitas, muchas veces silicificadas, $y$ otros tipos de rocas volcánicas, sedimentarias y/o metamórficas silicificadas, junto con variedades netamente silíceas (como la calcedonia y el ópalo).

De acuerdo con lo señalado previamente sobre la manufactura de artefactos en lutita en Posesión 3 y en bahía Laredo queda en evidencia la explotación en los sitios arqueológicos del estrecho de Magallanes de las variedades metamórficas de RGFO, de disponibilidad local en los depósitos costeros. Resta evaluar la circulación de las RGFO tipo Potrok Aike como un indicador más de la interacción del CVPA y el estrecho de Magallanes durante el Holoceno tardío.

\section{CONCLUSIONES}

Las nuevas evidencias aquí presentadas sobre la disponibilidad de rocas en el estrecho de Magallanes nos llevan a replantearnos algunas hipótesis previas donde se sostenía que este espacio habría funcionado como una fuente de aprovisionamiento lítico de importancia durante el Holoceno tardío. Si bien este puede ser el caso para las materias primas líticas diferentes a las RGFO, con respecto a estas últimas, si bien son más abundantes en la costa que en el CVPA, su baja calidad para la talla disminuye notablemente el rendimiento relativo de las fuentes potenciales de aprovisionamiento del estrecho de Magallanes. Este factor no imposibilita que muchas de las variedades metamórficas disponibles en los depósitos glacifluviales del estrecho de Magallanes hayan sido utilizadas para la manufactura de artefactos en los sitios localizados en la franja costera, pero se espera que la explotación de estos tipos haya sido parte principalmente de una estrategia expeditiva u oportunística, dado que son materias primas disponibles localmente en abundancia. Por el contrario, no se espera que estas variedades de RGFO se encuentren representadas en las puntas de proyectil, que mayoritariamente se encuentran manufacturadas en materias primas líticas de alta calidad como la obsidiana, las RGFO tipo Potrok Aike y la calcedonia. Al respecto interesa recordar aquí la referencia de Ortiz Troncoso (1972) sobre las evidencias de reutilización y reciclaje de las puntas de proyectil recuperadas en superficie en bahía Posesión (manufacturadas sobre basalto según este autor) como cuchillos y muescas. Posiblemente se trate de RGFO tipo Potrok Aike.

La interrelación de la información aquí presentada con aquella obtenida a partir del análisis de colecciones de artefactos arqueológicos procedentes de sitios del estrecho de Magallanes estudiadas recientemente en el Instituto de la Patagonia, junto con la información publicada por otros investigadores que han trabajado en la zona, nos permitirá en un futuro próximo profundizar el estudio de las estrategias tecnológicas de los cazadores-recolectores que explotaron este espacio en el marco de la oferta de rocas a escala local y regional.

\section{AGRADECIMIENTOS}

Nuestros mayores agradecimientos a los Drs. Flavia Morello, Fabiana Martin y Manuel San Román por todo el apoyo, asesoramiento y contribución para llevar a cabo los trabajos de campo y laboratorio en Chile. Asimismo a Pedro Cárdenas y Alfredo Prieto por la ayuda prestada en el CEHA y a la Dra. María Clara Etchichury por la identificación microscópica de una submuestra de los cortes delgados aquí presentados. Por último, agradecemos a los evaluadores anónimos del 
manuscrito que hay contribuido a su mejoramiento. Estas investigaciones fueron llevadas a cabo en el marco del proyecto PICT-ANPCyT 2008 n 15.

\section{BIBLIOGRAFÍA}

Alberti, J., \& Fernández, V. (2014). Propuesta clasificatoria para las materias primas líticas en Patagonia (Argentina). Arqueología, en prensa.

Aragón, E., \& Franco, N. (1997). Características de rocas para la talla por percusión y propiedades petrográficas. Anales del Instituto de la Patagonia, 25, 187-199.

Barberena, R. (2002). Los límites del mar. Isótopos estables en Patagonia Meridional. Buenos Aires: Sociedad Argentina de Antropología.

Barberena, R. (2008). Arqueología y Biogeografía Humana en Patagonia Meridional. Buenos Aires: Sociedad Argentina de Antropología.

Barberena, R. \& Borrero, L. (2010). Geoarqueología y distribuciones subsuperficiales de materiales arqueológicos: localidad Cabo Vírgenes. En L. Borrero \& J. Charlin (Eds.), Arqueología de Pali Aike y Cabo Vírgenes (pp.103-122). Buenos Aires: CONICETIMHICIHU.

Barberena, R., L'Heureux, L., \& Borrero, L. (2004). Expandiendo el alcance de las reconstrucciones de subsistencia. Isótopos estables y conjuntos arqueofaunísticos. En M.T. Civalero, P. Fernández \& A.G. Guráieb (Comps.), Contra viento y marea. Arqueología de Patagonia (pp. 417-434). Buenos Aires: INAPL \& SAA.

Barberena, R., Martin, F., \& Borrero, L. A. (2007). Estudio biogeográfico de conjuntos faunísticos: sitio Cóndor 1 (Pali Aike). En F. Morello, M. Martinic, A. Prieto, \& G. Bahamonde (Eds.), Arqueología de Fuego-Patagonia. Levantando piedras, desenterrando huesos... y develando arcanos (pp. 139-150). Punta Arenas: CEQUA.

Belardi, J. B, Carballo Marina, F., \& L'Heureux, G. (2011). Nuevos resultados arqueológicos en Cabo Vírgenes (Santa Cruz, Argentina): el sitio Cabo Vírgenes 20. Magallania, 39(2), 279-292.

Benn, D., \& Clapperton, C. (2000). Pleistocene glacitectonic landforms and sediments around central Magellan Strait, southernmost Chile: evidence for fast outlet glaciers with cold-based margins. Quaternary Science Reviews, 19, 591-612.

Bird, J. (1938). Antiquity and migrations of the early inhabitants of Patagonia. Geographical Review, 28, 250-275.
Bird, J. (1988). Travels and archaeology in South Chile. Iowa: University of Iowa Press.

Borella, F. (2010). Revisando la interpretación de los restos de lobos marinos en el registro arqueológico. El caso de Cabo Vírgenes. En L. Borrero \& J. Charlin (Eds.), Arqueología del campo volcánico Pali Aike y Cabo Vírgenes (Prov. Santa Cruz, Argentina)(pp. 123-135). Buenos Aires: CONICET-IMHICIHU.

Borella, F. \& L'Heureux, L. (2010). Primeros resultados osteométricos para una discusión de la estacionalidad de captura de otáridos en sitios arqueológicos de Patagonia: el caso de Cabo Vírgenes (Santa Cruz). En J. Bárcena \& H. Chiavazza, Arqueología Argentina en el Bicentenario de la Revolución de Mayo (pp. 18651870). Mendoza: FFyL UNCuyo-CONICET.

Borella, F., L'Heureux, L., \& Grandi, M. (2014). Osteometric analysis of south american sea lions (Otaria flavescens) pups from Patagonia. An assessment of their use as indicators for seasonality in archaeological sites. International Journal of Osteoarchaeology. doi: 10.1002/oa2392.

Borrero, L. A. \& Barberena, R. (2006). Hunter-gatherer home ranges and marine resources. Current Anthropology, 47(5), 855-867.

Borrero, L. A. \& Charlin, J. (Eds.) (2010). Arqueología del campo volcánico Pali Aike y Cabo Vírgenes (Prov. Santa Cruz, Argentina). Buenos Aires: CONICETIMHICIHU.

Borrero, L. A., Guichón, R. A., Tykot. R., Nelly, J., Prieto, A., \& Cárdenas, P. (2001). Estudios de dieta por medio de isótopos estables sobre huesos humanos de Patagonia Meridional y Tierra del Fuego. Anales del Instituto de la Patagonia, 29, 119-127.

Borrero, L. A., Franco, N., Barberena, R., Borella, F., Campan, P., Carballo Marina, F., ...Martin, F. (2008). Arqueología en Cabo Vírgenes y Cañadón Gap. En I. Cruz \& S. Caracotche, Arqueología de la costa patagónica. Perspectivas para la conservación (pp.213-228). Río Gallegos: UNPA.

Borrero, L. A., Barberena, R., Franco, N., Charlin, J., \& Tykot, R. (2009). Isotopes and Rocks: Geographical Organization of Patagonian Hunter-Gatherers. International Journal of Osteoarchaeology, 19, 309329.

Caldenius, C. (1932). Las Glaciaciones Cuaternarias en la Patagonia y Tierra del Fuego. Una Investigación Regional, Estratigráfica y Geocronológica. Una Comparación con la Escala Geocronológica Sueca. Buenos Aires: Ministerio de Agricultura de la Nación. 
Clapperton, C. (1993). Quaternary Geology and Geomorphology of South America. Amsterdam: Elsevier.

Clapperton, C., Sugden, D., Kaufman, D., \& McCulloch, R. (1995). The last Glaciation in central Magellan strait, southernmost Chile. Quaternary Research, 44, 133148.

Charlin, J. (2005). Aprovisionamiento de materias primas líticas en el campo volcánico de Pali Aike (Santa Cruz): una primera aproximación a partir del análisis de los núcleos. Werken, 7(2), 39-55.

Charlin, J. (2007). Una perspectiva espacial de la intensidad de uso de las materias primas líticas en el campo volcánico Pali Aike (Prov. Santa Cruz, Argentina). En F. Morello, M. Martinic, A. Prieto, \& G. Bahamonde (Eds.), Arqueología de Fuego-Patagonia. Levantando piedras, desenterrando huesos... y develando arcanos (pp. 129-138). Punta Arenas: CEQUA.

Charlin, J. (2009). Estrategias de aprovisionamiento y utilización de las materias primas líticas en el campo volcánico Pali Aike (Prov. Santa Cruz, Argentina). Oxford: Archaeopress.

Charlin, J. (2012). Materias primas líticas y uso del espacio en las nacientes del río Gallegos: el caso de laguna Cóndor (Estancia Glencross, Santa Cruz, Argentina). Magallania, 40(1), 163-184.

Charlin, J., \& D'Orazio, M. (2010). Fuentes primarias vs secundarias de aprovisionamiento lítico: una comparación geoquímica (Pali Aike, Santa Cruz). En Bertolino, S., Cattaneo, G. R., \& A. D. Izeta (Eds), La Arqueometría en Argentina y Latinoamérica (pp. 153-158). Córdoba: Editorial de la FFyH, Universidad Nacional de Córdoba.

Charlin, J. \& Barberena, R. (2011). ¿Cómo medimos la movilidad de las poblaciones humanas desde el registro arqueológico?: el caso de Pali Aike. En A. Guiance (Comp.), Movilidad y Migraciones (pp. 253-265). Buenos Aires: CONICET-IMHICIHU.

Charlin, J., \& Pallo, M. C. (2013). Disponibilidad de materias primas líticas y uso del espacio en el interfluvio Gallegos-Chico (Pali Aike, Santa Cruz, Argentina). En F. Zangrando, R. Barberena, A. Gil, G. Neme, M. Giardina, L. Luna, C. Otaola, S. Paulides, L. Salgán, \& A. Tivoli (Eds.), Tendencias teórico-metodológicas y casos de estudio en la arqueología de la Patagonia (pp. 307-316). Buenos Aires: Sociedad Argentina de Antropología.

Charlin, J., Borrero, L., \& Pallo, M. C. (2011). Ocupaciones humanas en el área noroccidental del río Gallegos (Prov. de Santa Cruz, Argentina). En L. Borrero, \& K.
Borrazzo (comps.), Bosques, montañas y cazadores. Investigaciones arqueológicas en Patagonia Meridional (pp. 179-210). Buenos Aires: CONICETIMHICIHU.

Constantinescu, F., Arroyo, M., Contreras, L., Morello, F., San Román, M., Martínez, I., \& Cárdenas, P. (1999). Estudios de impacto ambiental y arqueología en la costa norte del estrecho de Magallanes. Anales del Instituto de la Patagonia, 27, 209-219.

Coronato, A., Meglioli, A., \& Rabassa, J. (2004). Glaciations in the Magellan Straits and Tierra del Fuego, Southernmost South America. En J. Ehlers, \& P. Gibbard (Eds.), Quaternary glaciations-Extent and chronology, Part III (pp. 45-48). Amsterdam: Elsevier.

Feruglio, E. (1950). Descripción geológica de la Patagonia. Tomo III, Capítulos XXIII y XXIV. Buenos Aires: Dirección General de Yacimientos Petrolíferos Fiscales.

Fidalgo, F. \& Riggi, J. (1965). Los rodados patagónicos en la Meseta del Guenguel y alrededores (Santa Cruz). Revista de la Asociación Geológica Argentina, XX(3), 273-325.

Fidalgo, F. \& Riggi, J. (1970). Consideraciones geomórficas y sedimentológicas sobre los rodados patagónicos. Revista de la Asociación Geológica Argentina, XXV(4), 430-443.

Franco, N. (1998). La utilización de recursos líticos en Magallania. En L. A. Borrero (comp.), Arqueología de la Patagonia Meridional (Proyecto Magallania) (pp. 29-51). Concepción del Uruguay: Ed. Búsqueda de Ayllu.

Franco, N., \& Borrero, L. (1999). Metodología de análisis de la estructura regional de recursos líticos. En C. Aschero, M. Korstanje, \& P. Vuoto (Eds.) En Los tres Reinos: Prácticas de recolección en el cono Sur de América (pp. 27-37). San Miguel de Tucumán: Magna Publicaciones.

Jungers, W., Falsetti, A., \& Wall, C. (1995). Shape, relative size and size adjustments in morphometrics. Yearbook of Physical Anthropology, 38, 137-161.

Haury, C. E. (1995). Defining Lithic Procurement Technology. En T. Church (Ed.), Lithic Resource Studies: A Sourcebook for Archaelogists (pp. 26-31). Lithic Technology, Special Publication 3. Tulsa: Department of Anthropology, University of Tulsa.

Hayden, B. (1989). From chopper to celt: the evolution of resharpening techniques. En R. Torrence (Ed.), Time, energy and stone tools (pp. 7-16). Cambridge: Cambridge University Press.

Laming-Emperaire, A. (1965). La mission archéologique 
française au Chili austral. Journal de la Société des Américanistes, 54(1), 127-135.

Laming-Emperaire, A. (1968). Missions archéologiques françaises au Chili austral et au Brésil Méridional (datation des quelques sites par le radiocarbone). Journal de la Société des Américanistes, 57, 77-99.

L'Heureux, G. (2008). La arqueofauna del campo volcánico Pali Aike. El sitio Orejas de Burro 1, Santa Cruz, Argentina. Magallania, 36(1), 65-78.

L'Heureux, G., \& Franco, N. (2002). Ocupaciones humanas en el área de Cabo Vírgenes (Pcia. De Santa Cruz, Argentina): el sitio Cabo Vírgenes 6. Anales del Instituto de la Patagonia, 30, 183-201.

Marangunic, C. (1974). Los depósitos glaciales de la pampa magallánica. Revista Geográfica de Chile "Terra Australis”, 22-23, 5-11.

Martinic, M. (1984a). San Gregorio: centro Tehuelche meridional. Anales del Instituto de la Patagonia, 15, 11-25.

Martinic, M. (1984b). Noticia histórica sobre una prospección arqueológica realizada por Junios Bird a lo largo de la costa nororiental del estrecho de Magallanes (1937). Anales del Instituto de la Patagonia, 15, 43-45.

Martinic, M. (1995). Los Aónikenk. Historia y Cultura. Punta Arenas: Ediciones de la Universidad de Magallanes.

Massone, M. (1979). Panorama etnohistórico y arqueológico de la ocupación Tehuelche y Prototehuelche en la costa del Estrecho de Magallanes. Anales del Instituto de la Patagonia, 10, 69-107.

Massone, M. (1983). Antecedentes arqueológicos en torno a la ocupación española del siglo XVI en Punta Dungeness. Anales del Instituto de la Patagonia, 14, 49-54.

Massone, M. (1984). Los paraderos tehuelches y prototehuelches en la costa del Estrecho de Magallanes (Una aproximación teórica y metodológica). Anales del Instituto de la Patagonia, 15, 27-42.

McCulloch, R. \& Morello, F. (2009). Evidencia glacial y paleoecológica sobre ambientes tardiglaciales y del Holoceno temprano. Implicancias para el doblamiento temprano de Tierra del Fuego. En M. Salemme, F. Santiago, M. Álvarez, E. Piana, M. Vázquez \& E. Mansur (Comps.), Arqueología de la Patagonia. Una mirada desde el último confín (pp. 119-133). Ushuaia: Editorial Utopías.

McCulloch, R., Bentley, M., Purves, R., Hulton, N., Sugden, D., \& Clapperton, C. (2000). Climatic inferences from glacial and palaeoecological evidence at the last glacial termination, southern South America. Journal of Quaternary Science, 15(4), 409-417.

McCulloch, R., Fogwill, C., Sudgen, D., Bentley, M., \& Kubik, P. (2005a). Chronology of the last glaciation in central strait of Magellan and bahía Inútil, southernmost South America. Geografiska Annaler, 87 A(2), 289-312.

McCulloch, R., Bentley, M., Tipping, R., \& Clapperton, C. (2005b). Evidence for late-glacial ice dammed lakes in the central strait of Magellan and bahía Inútil, southernmost South America. Geografiska Annaler, $87 \mathrm{~A}(2), 336-362$.

Meglioli, A. (1992). Glacial geology and chronology of southernmost Patagonia and Tierra del Fuego, Argentina and Chile. Tesis doctoral. Universidad de Lehigh, Pensylvania, USA.

Meglioli, A. (1994). Glacial stratigraphy of central and northern Tierra del Fuego, Argentina. En J. Rabassa, M. Salemme, A. Coronato, C. Roig, A. Meglioli, G. Bujalesky, M. Zarate \& S. Gordillo (Eds.), Field Trip Guidebook. Symposium and field meeting "The termination of the Pleistocene in South America" (pp. 9-26). Ushuaia: IGCP Project 253.

Meglioli, A., Evenson, B., Zeitler, P., \& Rabassa, J. (1990). Cronología relativa y absoluta de los depósitos glaciarios de Tierra del Fuego, Argentina y Chile. Actas del $9^{\circ}$ Congreso Geológico Argentino, 2, 457-460.

Mercer, J. (1976). Glacial history of southernmost South America. Quaternary Research, 6, 125-166.

Nami, H. (1985). El subsistema tecnológico de la confección de instrumentos líticos y la explotación de los recursos del ambiente: una nueva vía de aproximación. Shincal, 2, 33-53

Ortiz Troncoso, O. (1972). Material lítico de Patagonia austral. Seis yacimientos de superficie. Anales del Instituto de la Patagonia, III(1-2), 49-82.

Prieto, A. (1988). Cazadores-recolectores del istmo de Brunswick. Anales del Instituto de la Patagonia, 18, 113-131.

Rabassa, J. \& Clapperton, C. (1990). Quaternary glaciations of the southern Andes. Quaternary Science Review, 9, 153-174.

Scasso, R. A., \& Limarino, C. O. (1997). Petrología y diagénesis de rocas clásticas. Buenos Aires: Asociación Argentina de Sedimentología.

Sudgen, D., Bentley, M., Fogwill, C., Hulton, N., McCulloch, R., \& Purves, R. (2005). Late-glacial glacier events in southernmost South America: A blend of 'northern' and 'southern' hemispheric climatic signals?. Geografiska Annaler, 87 A(2), 273-288. 